\title{
EXPANDING THE RECORD OF LARVAE OF FALSE FLOWER BEETLES WITH PROMINENT TERMINAL ENDS
}

\author{
ANA ZIPPEL ${ }^{1, *}$, CAROLIN HAUG ${ }^{1,2}$, CHRISTEL HOFFEINS ${ }^{3}$, HANS-WERNER HOFFEINS ${ }^{3}$ \\ \& JOACHIM T. HAUG ${ }^{1,2}$
}

\begin{abstract}
${ }^{1}$ Ludwig-Maximilians-Universität München, Biocenter, Großhaderner Str. 2, 82152 Planegg-Martinsried, Germany.
E-mails: AZ: ana.zippel@palaeo-evo-devo.info; CH: carolin.haug@palaeo-evo-devo.info; JTH: joachim.haug@palaeo-evo-devo.info

${ }^{2}$ GeoBio-Center at LMU, Richard-Wagner-Str. 10, 80333 München, Germany.

${ }^{3}$ Liseistieg 10, 22149 Hamburg, Germany; CH: chw.hoffeins@googlemail.com; HWH: hoffeins@aol.com

${ }^{*}$ Corresponding author.
\end{abstract}

Associate Editor: Cristina Lombardo

To cite this article: Zippel A., Haug C., Hoffeins C., Hoffeins H.-W. \& Haug J.T. (2022) - Expanding the record of larvae of false flower beetles with prominent terminal ends. Riv. It. Paleontol. Strat., 128(1): 81-104.

Keywords: Scraptiidae; Scraptiinae; Baltic amber; Burmite; quantitative morphology; shape analysis.

\begin{abstract}
Beetle larvae contribute to the overall biomass with a great share, yet they often stay unnoticed and underexplored. Larvae of the group Scraptiidae, also called false flower beetles, lead a life hidden in the wood, not easily accessible for observers. There, they contribute to wood decomposition and carbon cycling. Even though their ecological role is of great importance, these larvae have been comparably rarely studied. This is true for extant as well as fossil representatives of this group. It seems that this knowledge gap is not based on the limited availability of material but results from insufficiently studied material. Here we report new specimens, of which seven are extant and twelve are fossil. Fossil specimens are either from 40-million-year-old Baltic amber (Eocene) or 100-million-year-old Myanmar amber (Cretaceous), the latter representing the oldest record of these larvae. All specimens considered here possess a large, elongated terminal end. We performed an outline analysis of the shape of this terminal end for all so far known larval specimens sufficiently well preserved (in total 33 specimens: 17 extant, 14 Eocene, 2 Cretaceous). There is a recognisable difference between Eocene and extant specimens, yet it remains unclear whether this is due to different represented larval stages or an effect of evolution.
\end{abstract}

\section{INTRODUCTION}

Beetles are represented in the world with many well-known species and individuals. One less familiar group of beetles is Scraptiidae, named by Mulsant (1856). The group is rather small, with approximately 400 formally described species (Haug \& Haug 2019). Representatives of the group are also known as false flower beetles, probably because the adult animals are diurnal and often found on

Received: May 6, 2021; accepted: September 07, 2021 flowers and foliage (Young 1987). Indeed, most of our knowledge on false flower beetles is related to the adult animals as it is common for many aspects of biology (Minelli et al. 2006). There is only a small number of thorough descriptions of immatures of false flower beetles (recently summarised in Haug \& Haug 2019). This may be coupled with the fact that this part of the life cycle is mostly spent hidden within decaying wood (Buck 1954; Crowson 1955; Hayashi 1962; Vanin et al. 1996). There, the larvae are apparently playing a role in wood decomposition and therefore taking part in carbon cycling. 
Larvae of the ingroup Scraptiinae (and possibly some others) are easily identifiable at first glance, as they have posteriorly a large, prominent terminal end (Haug \& Haug 2019). The exact function of this terminal end is still not entirely clear, but it has been mentioned in connection to their saproxylic way of life (Haug \& Haug 2019) and to a self-defence mechanism through autotomy (Švácha 1995). Despite the apparent ecologically important function of the larvae and their unique morphology, the overall knowledge of these larvae is astonishingly low, and includes only four larvae from Baltic amber (Haug \& Haug 2019).

The situation in false flower beetles is a rather common one: there is in general a lack of information on larvae, compared to adults, and this applies to this group as well (Minelli et al. 2006). This can be recognised by the fact that larvae are rarely found in the literature (compared to adults), and larvae of many species indeed are still unknown. In some cases, it appears though that this knowledge gap is based on available but insufficiently studied material (e.g. Haug et al. 2018; Haug \& Haug 2019), i.e. not on difficulties of accessing the material, but on the tradition of what is in focus of most studies. This does not only account for the extant fauna, but even more so for the fossil record. Fossil immatures are often ignored and therefore may even appear rare, although they are in fact quite common (e.g. Baranov et al. 2020; 2021).

Beetles, like other representatives of Holometabola, are quite diverse with countless species adapted to various lifestyles. Additionally, immatures of holometabolans can lead lifestyles drastically different from those of the adults (e.g. Badano et al. 2018) and therefore significantly add to the biodiversity, in the sense of ecological diversity and ecosystem function diversity, of this group. This is also important for reconstructing ecosystems of the past (e.g. Baranov et al. 2021).

We here expand the record of available larvae of false flower beetles. This includes new extant specimens, new fossil larvae from 40-millionyear-old Eocene Baltic amber, but also new finds from 100-million-year-old Cretaceous Kachin amber (Myanmar). We furthermore explore the morphological variation of these larvae with Elliptic Fourier Analysis and discuss implications of these findings.

\section{Studied specimens ANd Methods}

\section{Material}

In this study, we report twelve new fossil larval specimens of the group Scraptiidae with large terminal ends. In addition, we consider seven new extant larvae. Additionally, for larger-scale comparison, we used specimens from literature (Böving \& Craighead 1931; Van Emden 1942; Peterson 1951; Hayashi 1980; Švácha 1995; Vanin et al. 1996; Weitschat \& Wichard 2002; Lawrence et al. 2011; Gröhn 2015), as compiled in Haug \& Haug (2019). One specimen from literature (Larsson 1978, his fig. 54c) has been overlooked by Haug \& Haug (2019) and is now included here (Fig. 1H).

The studied fossil specimens came from various collections: four specimens (SNSB-BSPG 2018 III 228, 232, 254, 336) came from the Staatliche Naturwissenschaftliche Sammlung Bayerns-Bayerische Staatssammlung für Paläontologie und Geologie München; five specimens (PED 0381, 0483, 0891, 0892, 1108) came from the Palaeo-Evo-Devo Research Group Collection of Arthropods at the Ludwig-Maximilians-Universität München; two specimens (SMF_Be 10659, 10735) came from the Senckenberg Forschungsinstitut und Naturmuseum Frankfurt; and one specimen (CCHH 1228-4) came from the Collection of Christel and Hans-Werner Hoffeins (to be deposited in the Senckenberg Deutsches Entomologisches Institut, Müncheberg (SDEI), Germany; inventory number SDEI Coleoptera \#303214).

The PED specimens were acquired legally from various traders over the online platforms ebay. com (amberabg, burmite-miner, goethgoeth) and etsy.com (Artur Michalski). Out of the twelve specimens, ten were found in Eocene Baltic amber, while two fossils originate from the Cretaceous period (Myanmar Kachin amber, PED 0483, PED 1108). Myanmar has been politically unstable especially in recent years, and it has been indicated that the trade with amber has an influence on this situation (Letter of the Society of Vertebrate Paleontology, SVP; Rayfield et al. 2020), although such a direct influence has been disputed (Poinar \& Ellenberger 2020; Peretti 2021). Also the usefulness of an originally proposed moratorium on research on amber (Rayfield et al. 2020) has been drawn into question (e.g. Haug et al. 2020a). A later suggestion of the SVP (Society of Vertebrate Paleontology's Myan- 
mar Working Group 2021) included that scientists should contribute official documents for export and import for each specimen. However, often single small and incomplete specimens achieve a value of few US dollars (in some cases even below one US dollar) and are therefore far below the threshold for receiving such documents. In other cases, numerous pieces are traded in a larger bulk, and also then no documents for an individual piece will be available. In principle, we agree with the SVP that we need to discuss about and develop procedures how to deal with fossils from conflict zones; yet we need to point out that the procedures suggested by the SVP may work well for high-priced pieces, but not for many pieces of lower monetary value, such as the small beetle larvae presented here. We therefore are unable to provide documents as suggested by the SVP due to common administrative procedures. Additionally, the current study was submitted and underwent the revision process before the new suggestions of the SVP had been announced.

Images of seven extant specimens were found in databases of two portals (Natural History Museum Data Portal and BoldSystems Public Data Portal). One specimen was found on www.data. nhm.ac.uk under the "Collection specimens" dataset and has been deposited at the Natural History Museum of London (NHMUK). The other six extant specimens were found on www.v3. boldsystems. org and have been deposited at the Zoologisches Forschungsmuseum Alexander Koenig (ZFMK), Bonn. Numbers of the extant specimens are mentioned below in the descriptions.

\section{Documentation methods}

Each of the new fossil specimens was documented with a Keyence VHX 6000 digital microscope. For the best result, all the specimens were photographed separately under different light conditions (coaxial cross-polarised light and unpolarised ring light), on the white and black background and from all accessible sides; all images are composite images and HDR images (Haug et al. 2013, 2020b). Images were automatically processed by the built-in software of the Keyence VHX 6000 digital microscope.

For a better understanding of the fossil specimens, the required images were further processed with Adobe Photoshop SC2. Segmental units and appendages of the larvae were marked in various colour nuances, which allows the reader to easier see our interpretation of the fossil itself. In addition, schemes of the dorsal habitus of the extant specimens from databases as well as the fossil specimen from Larsson (1978) were redrawn with the program Inkscape (Harrington et al. 2004-2005; http://www.inkscape.org/) in a similar fashion to other known specimens from the literature (Haug \& Haug 2019, their fig. 4).

\section{Measurements (Suppl. Tab. 1)}

We measured the total length of the larvae, from the most anterior tip of the labrum to the most posterior tip of the terminal end. We also measured the width of the head as a distance between the two laterally most protruding points of the head capsule. Unfortunately, not all images of the larvae had a readable scale available and therefore could not be measured. The same also applies to the specimen PED 0891 that had no visible head due to other amber inclusions. We plotted the head width against the total body length. Additionally, we measured the length of the terminal end as a distance between the most anterior and most posterior part of it. The specimen SMF_Be 10659 had an unclear border between the terminal end and the last abdomen segment. Therefore, this measurement is also missing.

\section{Shape analysis}

Some larvae of Scraptiidae, both fossil and extant, are characterized by a prominent abdomen terminal end (see Haug \& Haug 2019 for discussion). We compared the shape of this terminal end throughout time via a shape analysis. For this analysis, the terminal ends of all known fossil and extant species available in dorsal or ventral view (in total 33: 2 from the Cretaceous, 14 from the Eocene and 17 extant) were redrawn in Inkscape. Firstly, only one-half of each terminal end was redrawn from the image and consequently mirrored to make a bilaterally-symmetrical shape (otherwise a possible left-right asymmetry might provide a strong signal concealing other aspects). The posterior end of the larva SMF_Be 10659 is only seen as a light shadow through the amber and due to the uncertainty of its genuine form was left out from the shape analysis. The 33 shapes of terminal ends were saved as bitmap files and further processed in the program package SHAPE (C) National Agricultural Research 
Organization of Japan; Iwata \& Ukai 2002; cf. Braig et al. 2019; Haug et al. 2020b). The program enables an Elliptic Fourier Analysis and a Principal Component Analysis (PCA). The resulting PC1 and PC2 were further used for calculations. We plotted the first two dimensions (PCs) against each other and separately against total body length.

\section{REsults}

\section{General description of the specimens}

The body of the larva is elongated and differentiated into a head and a trunk region. The head bears paired antennae and mouth parts. The trunk can be further differentiated into the anterior thorax and the posterior abdomen. The thorax has three segments, each bearing a pair of locomotory appendages. The locomotory appendages are composed of coxa, trochanter, femur, tibia and claw-like tarsus. The abdomen has eight apparent segments and a prominent terminal end. Most of the specimens bear setae on the body surface, with some of them being more prominent and longer than the rest.

\section{Specific information on the extant specimens}

Larva of Scraptia fuscula (ZFMK-TIS-2568255): the image was provided by the Zoologisches Forschungsmuseum Alexander Koenig (ZFMK). A scale is present on the image, but is not readable. Therefore, the size of the specimen remains unknown. The specimen is only accessible in dorso-lateral view (Fig. $1 G$ ).

Mouth parts and the anntenae are not clearly visible. In dorsal view, the anterior part of the terminal end is wider than the posterior part. The posterior part has the shape of an arrow with multiple setae. The setae of the thorax segments and of the terminal end are longer than the setae on the head or the abdomen segments, about two times.

Larva of Scraptia fuscula (ZFMK-TIS-2574053): the image was provided by the Zoologisches Forschungsmuseum Alexander Koenig (ZFMK). A scale is present on the image, but is not readable. Therefore, the size of the specimen remains unknown. The specimen is only accessible in lateral view with the head in dorso-lateral view (Fig. 1A).

There are only indications of antennae. In dorsal view, the terminal end is ovoidal with its anterior part being somewhat wider than the posterior part. The terminal end bears numerous setae. Unfortunately, the specimen is damaged between abdomen segments 3 and 4, therefore we had to estimate certain aspects of the overall body shape. The larva appears to have been in a state right before moulting, two layers of cuticle are apparent, an inner and an outer one (we indicated this state in the drawing by using a lighter grey for the partly gaping cuticle).

Larva of Scraptia fuscula (ZFMK-TIS-2568252): the image was provided by the Zoologisches Forschungsmuseum Alexander Koenig (ZFMK). A scale is present on the image, but is not readable. Therefore, the size of the specimen remains unknown. The specimen is only accessible in dorso-lateral view (Fig. 1B).

Of the mouth parts, paired claw-like mandibles are very prominent. The trunk can be further differentiated into the anterior thorax and the posterior abdomen. In dorsal view, the terminal end is ovoidal, with its anterior part being somewhat wider than the posterior part. The setae on metathorax and abdomen segments are longer than the setae on other thorax segments, about two times. The setae on the posterior part of the terminal end are the longest ones of the entire animal.

Larva of Scraptia fuscula (ZFMK-TIS-2568253): the image was provided by the Zoologisches Forschungsmuseum Alexander Koenig (ZFMK). A scale is present on the image, but is not readable. Therefore, the size of the specimen remains unknown. The specimen is only accessible in dorsal view (Fig. 1C).

Antennae and mouth parts are not clearly visible. In dorsal view, the terminal end is ovoidal, with its anterior part being wider than the posterior part. The posterior part forms a triangle. The postero-lateral setae of each abdomen segment and setae of the posterior part of the terminal end are the longest.

Larva of Scraptia fuscula (ZFMK-TIS-2573887): the image was provided by the Zoologisches Forschungsmuseum Alexander Koenig (ZFMK). A scale is present on the image, but is not readable. Therefore, the size of the specimen remains unknown. The specimen is only accessible in dorsal view (Fig. 1E). 


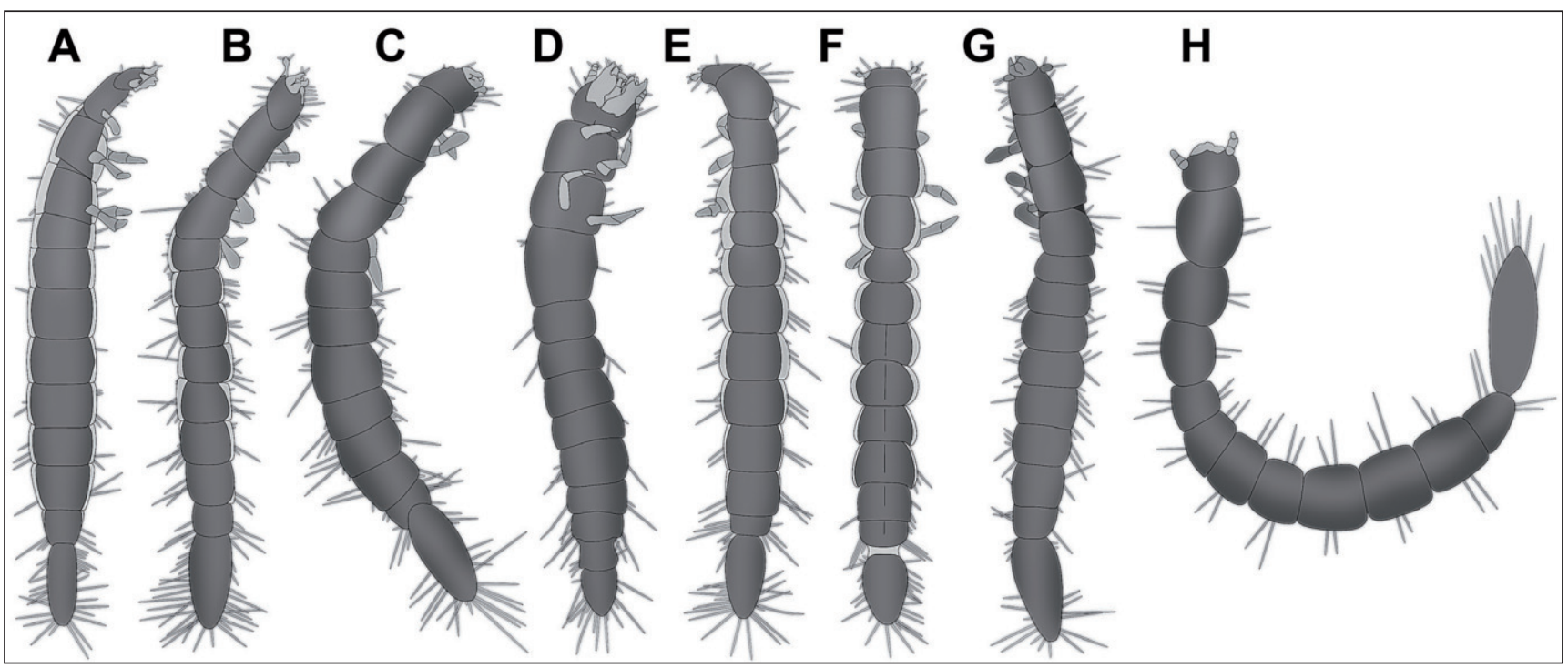

Fig. 1 - Larvae of Scraptiidae; a schematic representation of seven extant specimens extracted from databases and one "new" fossil specimen from the literature. A-G) Extant specimens. A - ZFMK-TIS-2574053. B - ZFMK-TIS-2568252. C - ZFMK-TIS-2568253. D NHMUK 010133900. E - ZFMK-TIS-2573887. F - ZFMK-TIS-2574081. G - ZFMK-TIS-2568255. H) Fossil specimen in Baltic amber (Eocene) from Larsson (1978).

The head is only partially accessible. Only one antenna is apparent. Mouth parts are not visible. On mesothorax and metathorax only one appendage is apparent. On the first four abdomen segments, outer and inner cuticle can be differentiated. The posterior four abdomen segments do not show a clear partition of the outer and inner cuticle. In dorsal view, the terminal end is ovoidal with its anterior part being somewhat wider than the posterior part. The posterior part forms a triangle. The postero-lateral setae of each body segment and setae of the posterior part of the terminal end are the longest.

Larva of Scraptia fuscula (ZFMK-TIS-2574081): the image was provided by the Zoologisches Forschungsmuseum Alexander Koenig (ZFMK). A scale is present on the image, but is not readable. Therefore, the size of the specimen remains unknown. The specimen is only accessible in dorsal view (Fig. 1F).

Mouth parts are not visible. In dorsal view, the terminal end is ovoidal with its anterior part being wider than the posterior part. Setation is only visible on the antennae, lateral edges of the head capsule, last three abdomen segments and the terminal end. Some of the setae are more prominent and longer than the rest, for example, the setae of the terminal end. The larva appears to have been in a state right before moulting, two layers of cuticle are apparent, an inner and an outer one (we indicated this state in the drawing by using a lighter grey for the partly gaping cuticle).

Larva NHMUK 010133900 of unknown species: the images were provided by the Natural History Museum of London (NHMUK). This specimen appears somewhat older and has been preserved on a microscopic slide. There are three photographs of the specimen available. One shows the entire microscopic slide, the second shows the head and the third the trunk. According to the provided scales, the total body length is approximately $7.9 \mathrm{~mm}$, and the width of the head is approximately $0.9 \mathrm{~mm}$. The head is accessible in dorsal view and the trunk in dorso-lateral view (Fig. 1D).

From the mouth parts, most prominent are strong and serrated paired mandibles. Partially covered by mandibles are a pair of maxillae with maxillary palps and numerous setae. In between the mandibles, a labium is apparent with two labial palps. Only prothorax and mesothorax have paired locomotory appendages, the pair on the metathorax appears ripped off. In dorsal view, the terminal end is ovoidal, with its anterior part being somewhat wider than the posterior part. The setae of the three posterior abdomen segments and the setae of the terminal end are more prominent and longer than the rest. 


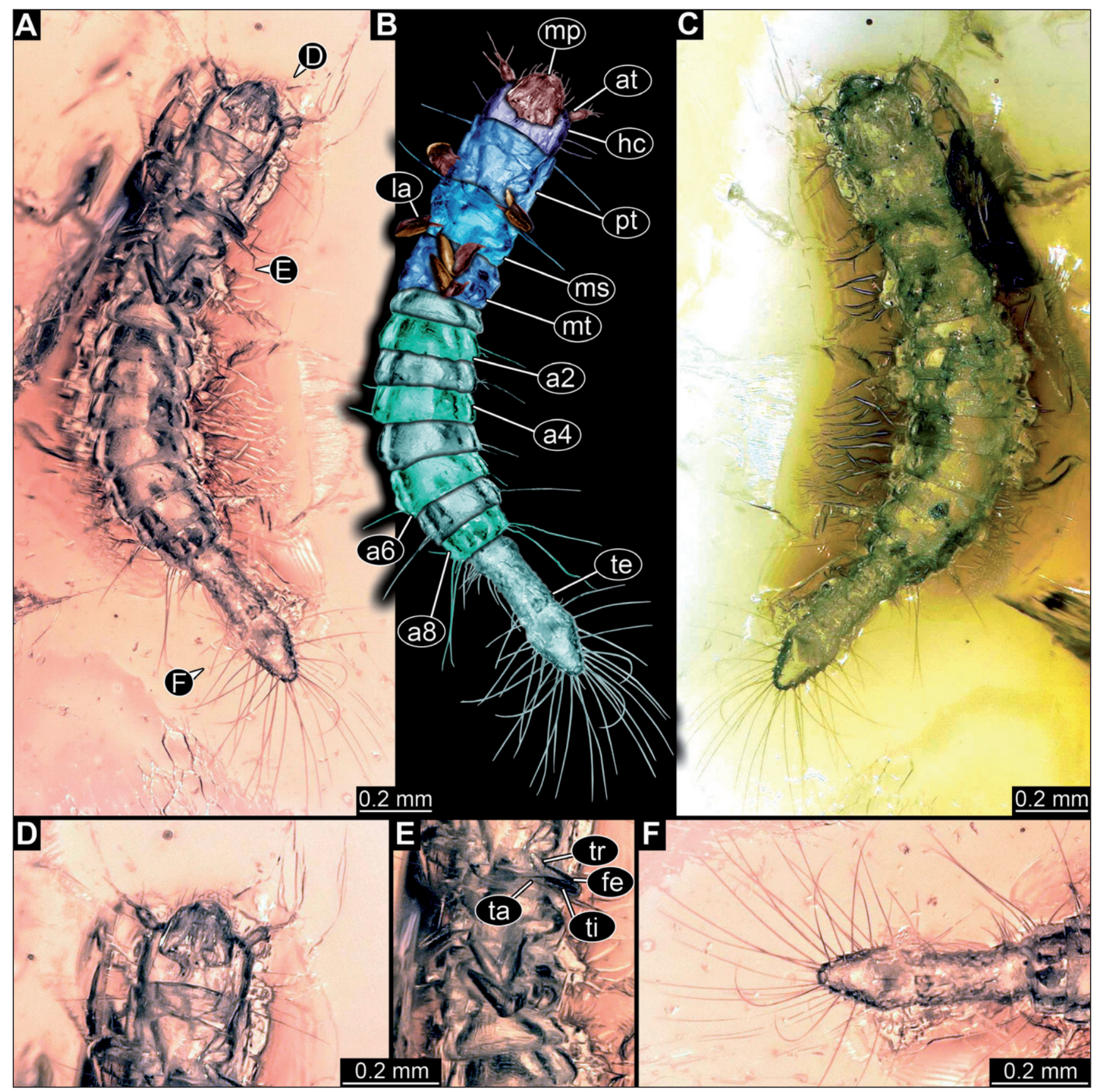

Fig. 2 - Larva of Scraptiidae preserved in Baltic amber, specimen SNSB-BSPG 2018 III 232; all composite images. A) Habitus in ventral view, cross-polarised co-axial light. B) Colour-marked version of (A). C) Habitus in dorsal view, cross-polarised co-axial light. D-F) Closeups. D - Head in ventral view. E - Locomotory appendages. F - Terminal end in ventral view. Abbreviations: $\mathrm{a} 2-8=$ abdomen segments 2-8; at = antenna; $\mathrm{fe}=$ femur; $\mathrm{hc}=$ head capsule; $\mathrm{la}=$ locomotory appendage; $\mathrm{mp}=$ mouth parts; $\mathrm{ms}=$ mesothorax; $\mathrm{mt}=$ metathorax; $\mathrm{pt}=$ prothorax; $\mathrm{ta}=$ tarsus; $\mathrm{te}=$ terminal end; $\mathrm{ti}=$ tibia; $\mathrm{tr}=$ trochanter.

Specific information on the fossil specimens

Larva SNSB-BSPG 2018 III 232 of unknown species: the specimen is preserved in Eocene Baltic amber. The larva is accessible in dorsal and ventral view. The entire specimen is approximately $1.8 \mathrm{~mm}$ long, with a head width of approximately $0.2 \mathrm{~mm}$ (Fig. 2A-C).

The head bears paired antennae and mouth parts (Fig. 2D). The locomotory appendages are presented in the Fig. 2E. In dorsal view, the terminal end is elongated with its anterior part being rounder, shorter and wider than the middle part. The posterior part of the terminal end has an arrow-like shape (Fig. 2F). Setation is only visible on the antennae, anterior edge of mouth parts, lateral edges of the head capsule, anterior three thorax segments, eight abdomen segments and the terminal end. Some of them are more prominent and longer than the rest, 


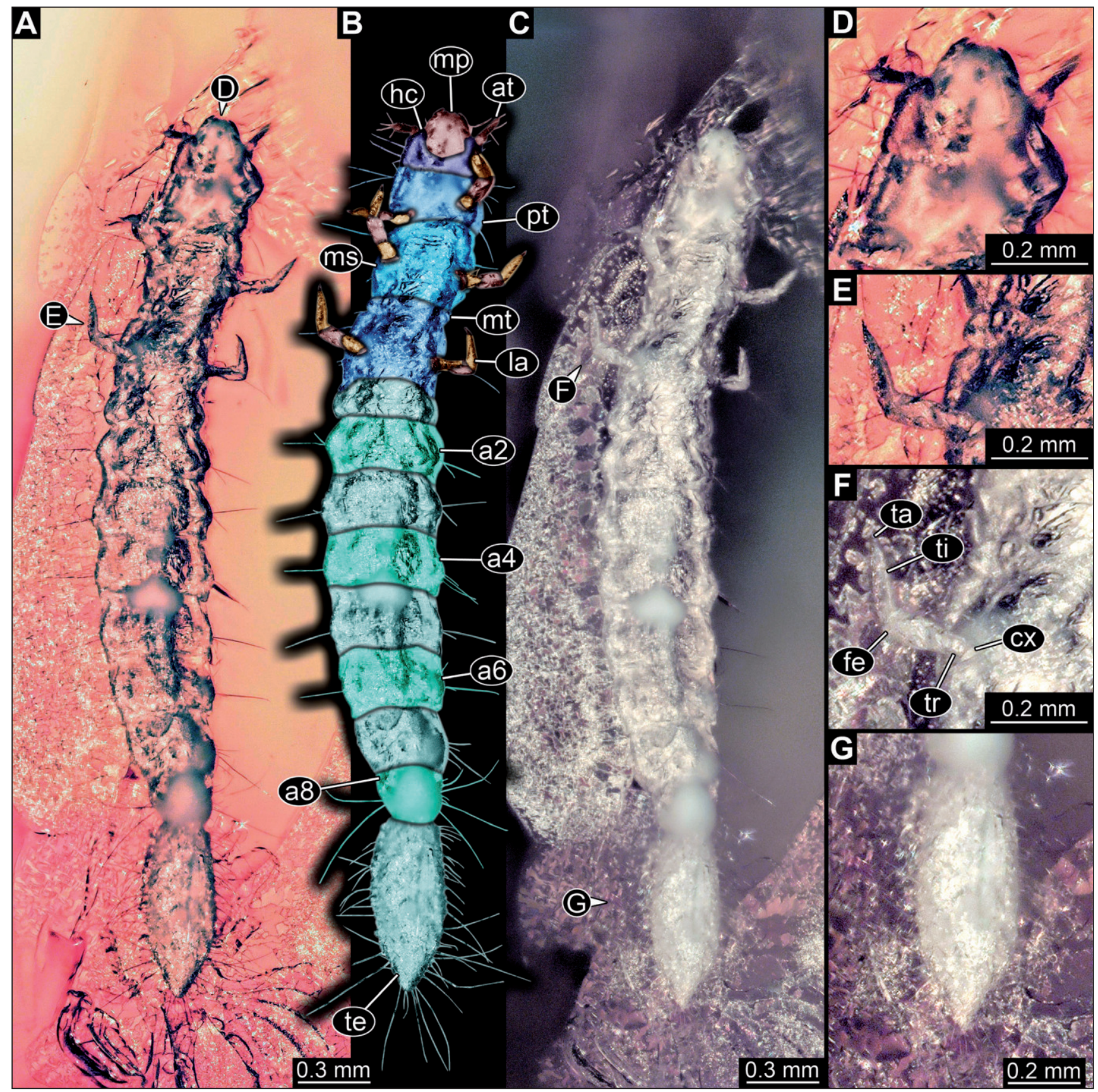

Fig. 3 - Larva of Scraptiidae preserved in Baltic amber, specimen SNSB-BSPG 2018 III 254; all composite images. A) Habitus in ventral view, cross-polarised co-axial light on white background. B) Colour-marked version of (A). C) Habitus in ventral view, cross-polarised coaxial light on black background. D-G) Close-ups. D - Head in ventral view. E - Locomotory appendage of metathorax photographed under the same conditions as in (A). F - Locomotory appendage of metathorax photographed under the same conditions as in (C). G - Terminal end in ventral view. Abbreviations: a2 $-8=$ abdomen segments $2-8$; at $=$ antenna; $\mathrm{cx}=\mathrm{coxa}$; $\mathrm{fe}=$ femur; hc $=$ head capsule; $\mathrm{la}=$ locomotory appendage $\mathrm{mp}=$ mouth parts; $\mathrm{ms}=$ mesothorax; $\mathrm{mt}=$ metathorax $; \mathrm{pt}=$ prothorax $; \mathrm{ta}=$ tarsus; $\mathrm{te}=$ terminal end; $\mathrm{ti}=$ tibia; $\mathrm{tr}=$ trochanter.

for example, the setae of the proximal part of the terminal end.

Larva SNSB-BSPG 2018 III 254 of unknown species: the specimen is preserved in Eocene Baltic amber. The specimen is accessible only in ventral view. Even though the outlines of the specimen are well accessible, the details of the head and the abdomen segments 5 and 8 are concealed (Fig. 3A-C). The entire specimen is approximately $3.6 \mathrm{~mm}$ long, with a head width of approximately $0.3 \mathrm{~mm}$. The antennae and mouth parts are clearly visible (Fig. 3D). The thorax bears locomotory appendages (Fig. $3 \mathrm{E}, \mathrm{F})$. In ventral view, the terminal end is elongated 


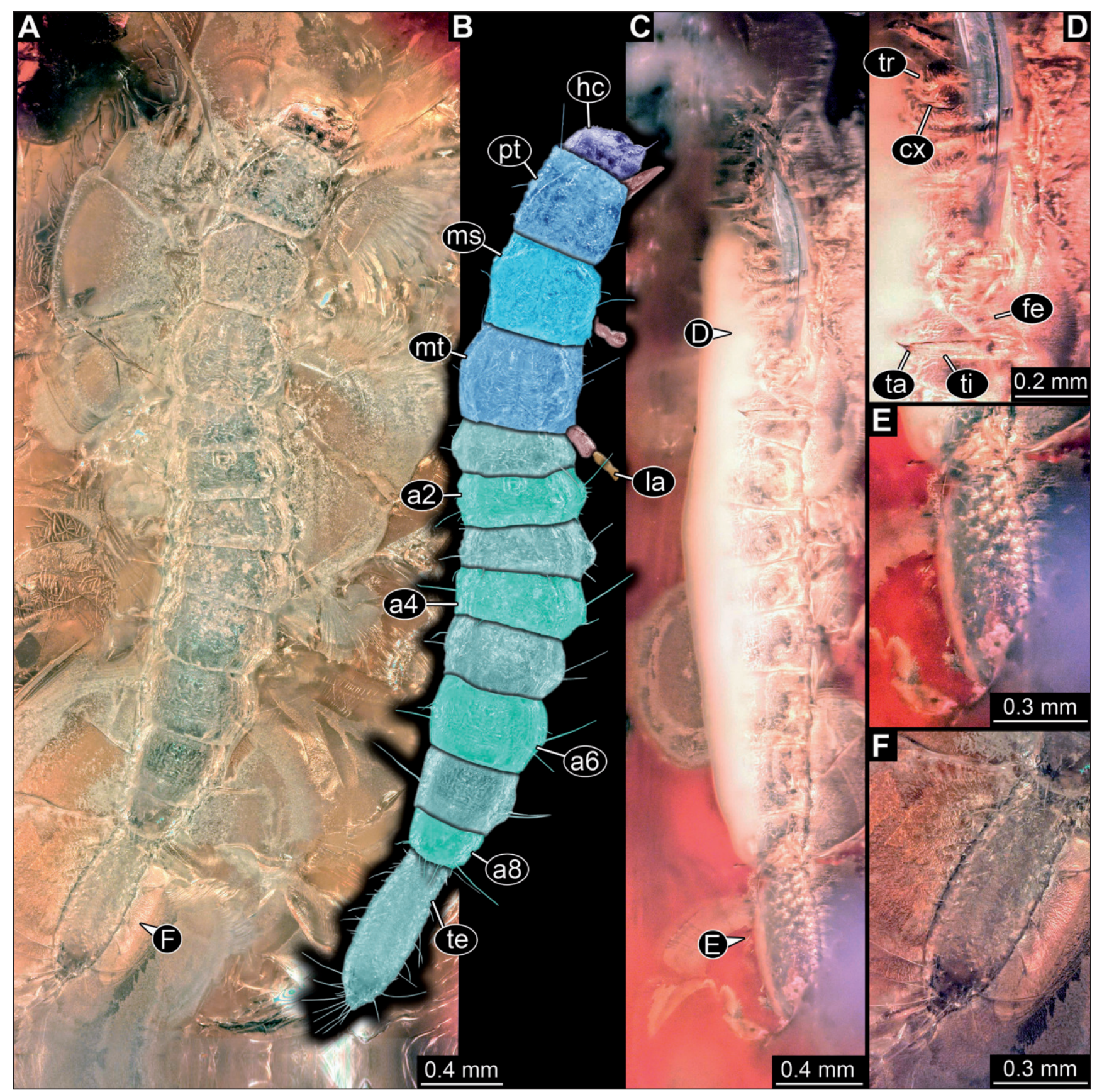

Fig. 4 - Larva of Scraptiidae preserved in Baltic amber, specimen SNSB-BSPG 2018 III 228; all composite images. A) Habitus in dorsal view, non-polarised ring illumination on white background. B) Colour-marked version of (A). C) Habitus in lateral view, non-polarised ring illumination on black background. D-F) Close-ups. D - Locomotory appendages. E - Terminal end in lateral view. F - Terminal end in dorsal view. Abbreviations: a2-8 = abdomen segments $2-8$; $\mathrm{fe}=$ femur; hc $=$ head capsule; la $=$ locomotory appendage; $\mathrm{ms}=$ mesothorax; $\mathrm{mt}=$ metathorax; $\mathrm{pt}=$ prothorax; $\mathrm{ta}=$ tarsus; $\mathrm{ti}=$ tibia; $\mathrm{te}=$ terminal $\mathrm{end} ; \mathrm{tr}=$ trochanter.

with the middle part being widest and its posterior part forming a triangle (Fig. 3G). The most prominent setae are on the lateral edges of the segments, with the longest being on the abdomen segment 8 and the posterior part of the terminal end.

Larva SNSB-BSPG 2018 III 228 of unknown species: the specimen is preserved in Eocene Baltic amber. The specimen is accessible in dorsal (Fig.
4A, B) and lateral view (Fig. 4C). Its ventral side is largely concealed by Verlumung (Fig. 4C). The entire specimen is approximately $4.6 \mathrm{~mm}$ long, with a head width of approximately $0.4 \mathrm{~mm}$.

Only one antenna is apparent. Mouth parts are not visible. Details of the locomotory appendages are well accessible (Fig. 4D). In dorsal view, the terminal end is elongated with its posterior part forming a triangle (Fig. 4E, F). The most prominent 




Fig. 5 - Larva of Scraptiidae preserved in Baltic amber, specimen SNSB-BSPG 2018 III 336; all composite images. A) Habitus in lateral view, cross-polarised co-axial light on black background. B) Colour-marked version of (A). C) Habitus in lateral view, non-polarised ring illumination on black background. D-F) Close-ups. D - Head in lateral view. E - Locomotory appendages. F - Terminal end in lateral view. Abbreviations: a2 $-8=$ abdomen segments $2-8$; at $=$ antenna; $\mathrm{fe}=$ femur; hc $=$ head capsule; la $=$ locomotory appendage; $\mathrm{ms}=$ mesothorax; $\mathrm{mt}=$ metathorax; $\mathrm{pt}=$ prothorax $; \mathrm{ta}=$ tarsus; $\mathrm{te}=$ terminal $\mathrm{end} ; \mathrm{ti}=$ tibia; $\mathrm{tr}=$ trochanter.

setae are on the lateral edges of the segments and the posterior part of the terminal end.

Larva SNSB-BSPG 2018 III 336 of unknown species: the specimen is preserved in Eocene Baltic amber. The specimen is accessible in lateral view (Fig. 5A-C). The entire specimen is approximately $2.7 \mathrm{~mm}$ long, with a head width of approximately $0.3 \mathrm{~mm}$.
The antennae are clearly visible (Fig. 5D), whereas the mouth parts are not. The locomotory appendages are well accessible (Fig. 5E). In lateral view, the terminal end is elongated with its posterior part forming a triangle (Fig. 5F). Setation is only visible on the head capsule, antennae, posterior abdomen segments and terminal end. Some of them are more prominent and longer than the rest, for example, the setae of the posterior part of the terminal end. 


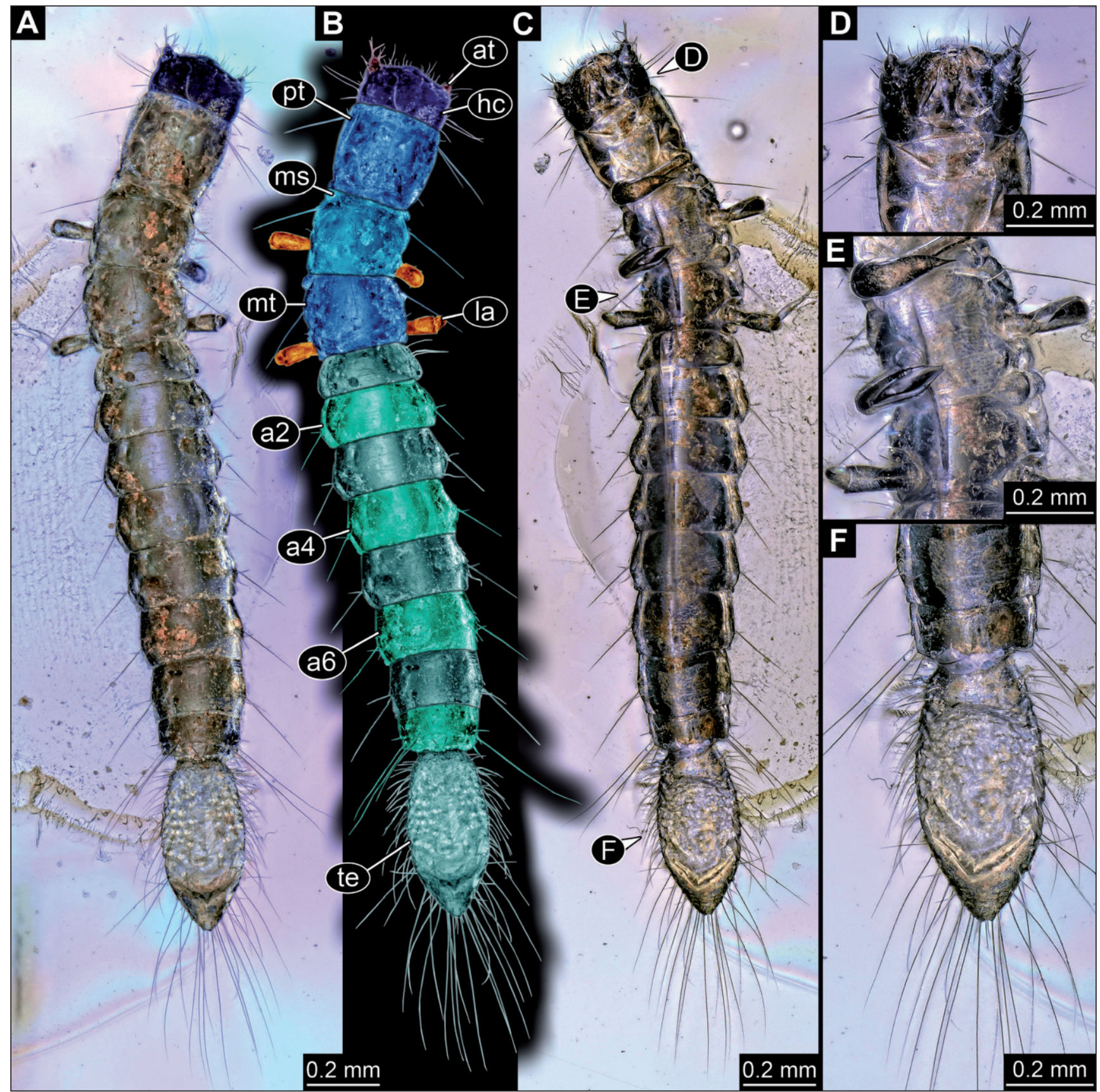

Fig. 6 - Larva of Scraptiidae preserved in Baltic amber, specimen CCHH 1228-4; all composite images. A) Habitus in dorsal view, crosspolarised co-axial light on white background. B) Colour-marked version of (A). C) Habitus in ventral view, cross-polarised co-axial light on white background. D-F) Close-ups. D - Head in ventral view. E - Locomotory appendages. F - Terminal end in ventral view. Abbreviations: a2-6 = abdomen segments 2-6; at = antenna; hc = head capsule; la = locomotory appendage; $\mathrm{ms}=$ mesothorax; $\mathrm{mt}$ $=$ metathorax; $\mathrm{pt}=$ prothorax; $\mathrm{te}=$ terminal $\mathrm{end}$.

Larva CCHH 1228-4/SDEI 303214 of unknown species: the specimen is preserved in Eocene Baltic amber, embedded in polyester resin (Hoffeins 2001). The specimen is accessible both in dorsal and in lateral view (Fig. 6A-C). The entire specimen is approximately $2.4 \mathrm{~mm}$ long, with a head width of approximately $0.2 \mathrm{~mm}$.

The antennae and mouth parts (Fig. 6D) and locomotory appendages are well accessible
(Fig. 6E). From a ventral view, the terminal end is ovoidal, with its middle part being the widest and its posterior part forming a triangle (Fig. 6F). The most prominent setae are on the lateral edges of the segments and on the posterior part of the terminal end.

Larva PED 0381 of unknown species: the specimen is preserved in Eocene Baltic amber. The spec- 




Fig. 7 - Larva of Scraptiidae preserved in Baltic amber, specimen PED 0381; all composite images. A) Habitus in ventral view, non-polarised ring illumination on white background. B) Colour-marked version of (A). C) Habitus in dorsal view, cross-polarised co-axial light on white background. D-F) Close-ups. D - Head in ventral view as original image (left) and colour-marked version (right). E - Locomotory appendages. F - Terminal end in dorsal view. Abbreviations: a2 $-8=$ abdomen segments $2-8$; at $=$ antenna; fe $=$ femur; hc $=$ head capsule; $\mathrm{la}=$ locomotory appendage; $\mathrm{lb}=$ labium; $\mathrm{mp}=$ mouth parts; $\mathrm{ms}=$ mesothorax $\mathrm{mt}=$ metathorax $\mathrm{mx}=\operatorname{maxilla} ; \mathrm{pl}=\mathrm{palp}$; $\mathrm{pt}=$ prothorax; $\mathrm{ta}=$ tarsus; $\mathrm{te}=$ terminal end; $\mathrm{t}=$ tibia .

imen is accessible both in ventral (Fig. 7A, B) and in dorsal view (Fig. 7C). Part of the ventral view is concealed by Verlumung (Fig. 7A). The entire specimen is approximately $2.8 \mathrm{~mm}$ long, with a head width of approximately $0.3 \mathrm{~mm}$.

From the visible mouth parts most prominent are two maxillae with maxillary palps, and the labium (Fig. 7D). Also the locomotory appendages are well accessible (Fig. 7E). In dorsal view, the terminal end is ellipsoidal with its middle part being the widest (Fig. 7F). The longest setae are on the posterior part of the terminal end.

Larva PED 0483 of unknown species: the specimen is preserved in Cretaceous Myanmar amber.
The specimen is accessible only in lateral view (Fig. 8A-C). Part of the specimen is concealed by other inclusions in amber (Fig. 8C). The entire specimen is approximately $3.9 \mathrm{~mm}$ long, with a head width of approximately $0.2 \mathrm{~mm}$.

The head bears paired antennae and a structure that we were not able to identify (Fig. 9A). The locomotory appendages are well accessible (Fig. $9 \mathrm{~B})$. In lateral view, the terminal end is elongated, almost triangular with its anterior part being wider than the posterior part (Fig. 9C). The longest setae are on the posterior end of the terminal end.

Larva PED 0891 of unknown species: the specimen is preserved in Eocene Baltic amber. The spec- 


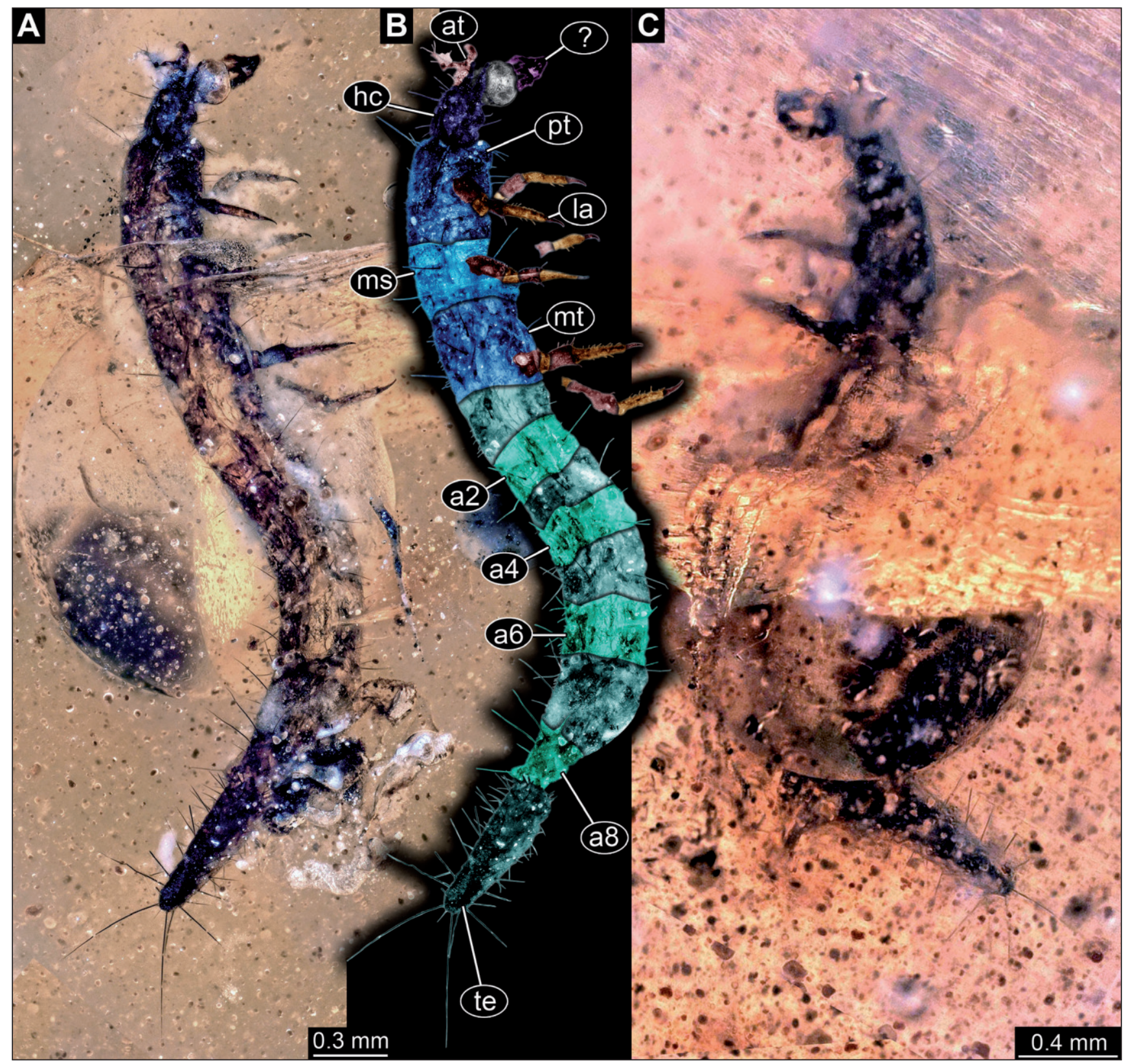

Fig. 8 - Larva of Scraptiidae preserved in Myanmar amber, specimen PED 0483; all composite images. A) Habitus in lateral view, non-polarised ring illumination on black background. B) Colour-marked version of (A). C) Habitus in lateral view, non-polarised ring illumination on white background. Abbreviations: a2 $-8=$ abdomen segments $2-8$; at $=$ antenna; hc $=$ head capsule; la = locomotory appendage; $\mathrm{ms}$ $=$ mesothorax $\mathrm{mt}=$ metathorax; $\mathrm{pt}=$ prothorax; te $=$ terminal end $;$ ? = unknown structure

imen is accessible only in ventral view (Fig. 10A-C). Part of the specimen is concealed by other inclusions in amber and therefore the size of the specimen remains unknown.

Only the trunk of the specimen is accessible. On prothorax only a single appendage is apparent (Fig. 10D). From a ventral view, the terminal end is elongated but details of its posterior part are not apparent (Fig. 10E). Setation is only visible on the third, seventh and eighth abdomen segment and the terminal end. The setae of the antero-lateral edge of the abdomen segment 8 and the setae of the distal edge of the terminal end are most prominent.

Larva PED 0892 of unknown species: the specimen is preserved in Eocene Baltic amber. The specimen is accessible only in ventral view (Fig. 11A, B). Part of the specimen is concealed by Verlumung (Fig. 11A). The entire specimen is approximately $3.7 \mathrm{~mm}$ long, with a head width of approximately $0.3 \mathrm{~mm}$.

Laterally on the head are prominent darker regions (possible stemmata or groups of stemma- 




Fig. 9 - Close-up details of larva of Scraptiidae, specimen PED 0483; all composite images. A) Head in lateral view. B) Locomotory appendages. C) Terminal end in lateral view. Abbreviations: $\mathrm{fe}=$ femur; $\mathrm{ta}=$ tarsus; te $=$ terminal end; $\mathrm{ti}=\mathrm{tibia}$; $\mathrm{tr}=$ trochanter; ? = unknown structure.

ta). The paired antennae and mouth parts are well accessible (Fig. 12A). Most prominent are a pair of maxillae with maxillary palps, and a labium (Fig. $12 \mathrm{~B})$. In ventral view the terminal end is elongated and of pentagonal shape with its most posterior part forming a triangle (Fig. 12C). The longest setae are on the abdomen segment 8 and the posterior part of the terminal end.

Larva PED 1108 of unknown species: the specimen is preserved in Cretaceous Myanmar amber. The specimen is accessible both in dorsal (Fig. 13 A, B) and in ventral view (Fig. 13C). The posterior part of the specimen is concealed by other inclusions in amber (Fig. 13A, B). The entire specimen is approximately $4 \mathrm{~mm}$ long, with a head width of approximately $0.6 \mathrm{~mm}$.

The paired antennae and mouth parts are accessible (Fig. 14A, C). The locomotory appendages are well accessible ( Fig. 14D, E). In dorsal view, the terminal end is elongated triangle-shaped with its anterior part being the widest (Fig. 14B). The most prominent setae are on the lateral edges of segments and on the posterior part of the terminal end.

Larva SMF_Be 10659 of unknown species: the specimen is preserved in Eocene Baltic amber. The specimen is accessible only in dorsal view (Fig. 15A,
B). The posterior part of the specimen is concealed by other inclusions in amber and only the indications of the body outline are visible (Fig. 15A). The entire specimen is approximately $2.1 \mathrm{~mm}$ long, with a head width of approximately $0.3 \mathrm{~mm}$.

The body of the larva is elongated and differentiated into a head and a trunk region. The antennae and mouth parts are accessible (Fig. 15C). On metathorax only a single locomotory appendage is apparent (Fig. 15D). In dorsal view, the terminal end is ovoidal with its middle part being wider than its anterior or posterior part. Setation is only visible on lateral edges of the head capsule, antennae, thorax segments and apparent abdomen segments. Most prominent are the setae of the abdomen segments.

Larva SMF_Be 10735 of unknown species: the specimen is preserved in Eocene Baltic amber. The specimen is accessible in lateral view (Fig. 16A, B). There is also a dorso-lateral view of the head and thorax region and a ventral view of the abdomen region available due to the pose in which the larva was preserved (Fig. 16C). From the lateral view, the dorsal part of the thorax segments is concealed by Verlumung and a bubble. Verlumung also conceals a part of the abdomen segments. The entire specimen is approximately $3 \mathrm{~mm}$ long, with a head width of approximately $0.3 \mathrm{~mm}$. 


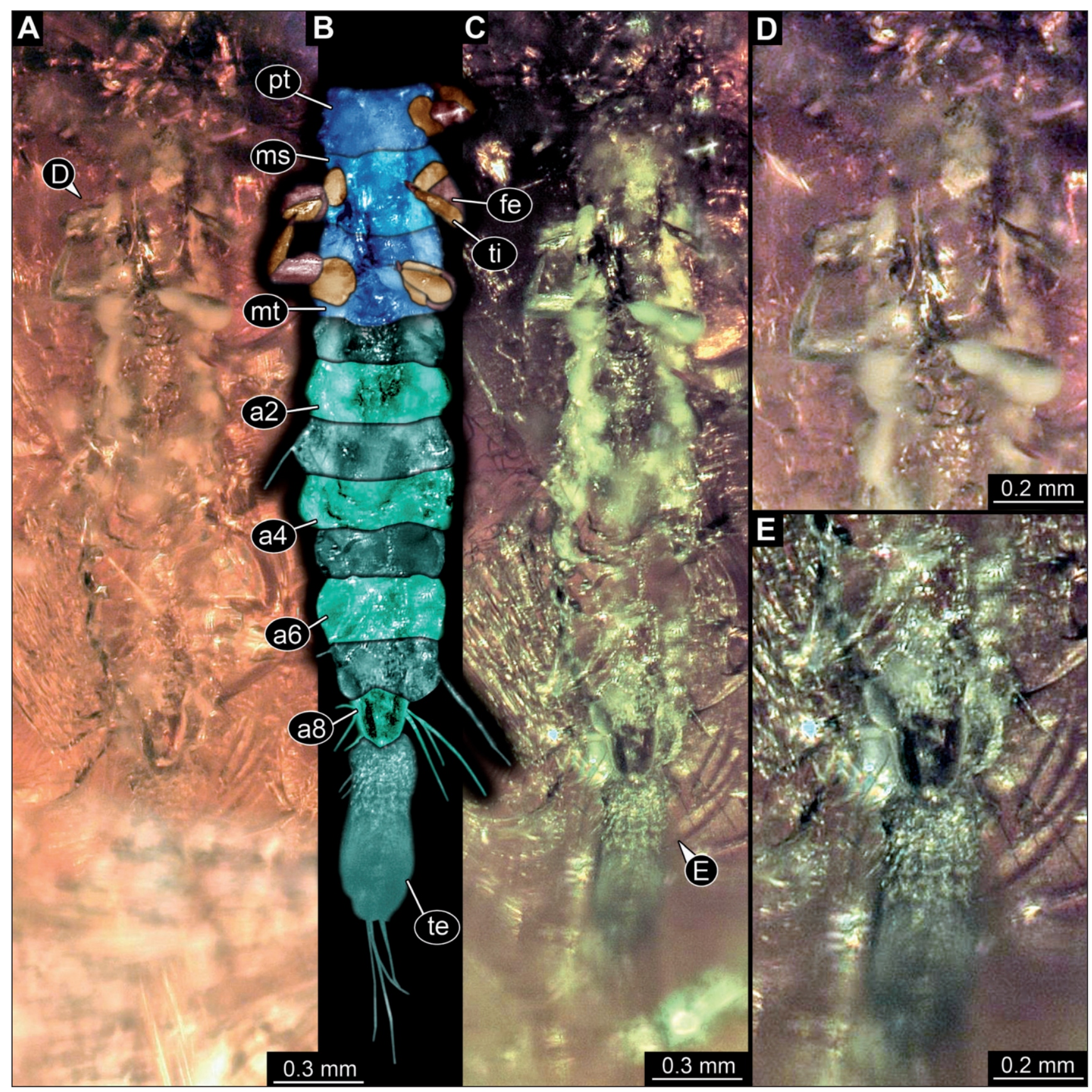

Fig. 10 - Larva of Scraptiidae preserved in Baltic amber, specimen PED 0891; all composite images. A) Habitus in ventral view, non-polarised ring illumination on black background. B) Colour-marked version of (A). C) Habitus in ventral view, cross-polarised co-axial light on white background. D-E) Close-ups. D - Locomotory appendages. E - Terminal end in ventral view. Abbreviations: a2-8 = abdomen segments $2-8 ; \mathrm{fe}=$ femur; $\mathrm{ms}=$ mesothorax $\mathrm{mt}=$ metathorax; $\mathrm{pt}=$ prothorax; $\mathrm{te}=$ terminal $\mathrm{end} ; \mathrm{ti}=$ tibia.

The antennae and mouth parts (Fig. 16D) and thorax locomotory appendages are well accessible (Fig. 16E). From a lateral view, the terminal end is ovoidal with its anterior part being the widest and most posterior part the narrowest (Fig. 16F). Setation is only visible on the head capsule, antennae, thorax segments, posterior three abdomen segments and the terminal end. The longest are the setae of the posterior part of the terminal end.

\section{Shape analysis}

The shape analysis of 33 specimens resulted in five effective Principal Components (PCs). All the values and measurements can be found in Supplementary Table 1.

PC1 explains $71.54 \%$ of the total variance. It is mainly influenced by the length and shape of the anterior part of the terminal end. A high value indicates a straight anterior part of the terminal end and 


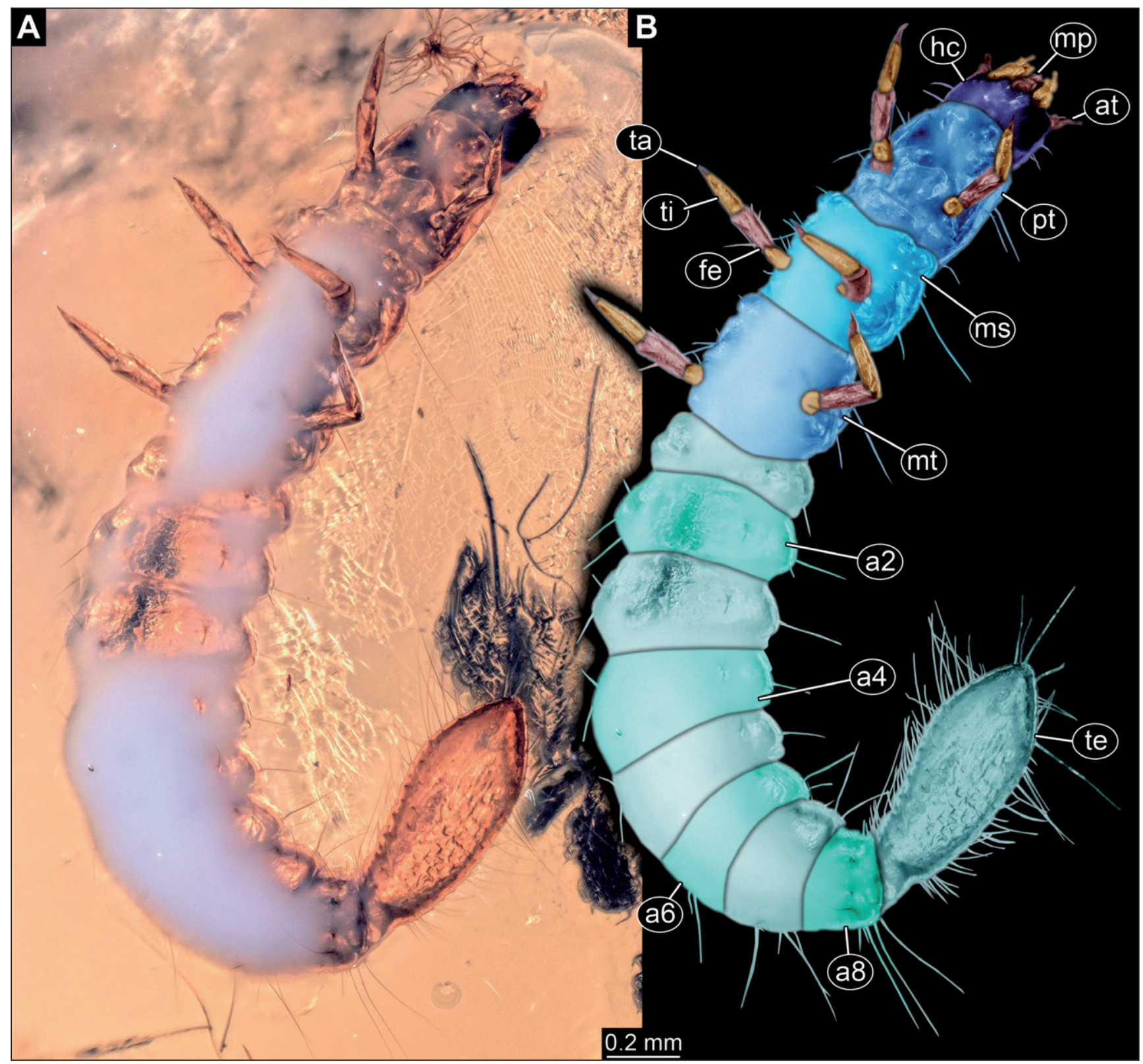

Fig. 11 - Larva of Scraptiidae preserved in Baltic amber, specimen PED 0892; all composite images. A) Habitus in ventral view, non-polarised ring illumination on white background. B) Colour-marked version of (A). Abbreviations: $a 2-8=$ abdomen segments 2-8; at $=$ anten$\mathrm{na} ; \mathrm{fe}=$ femur; $\mathrm{hc}=$ head capsule; $\mathrm{mp}=$ mouth parts; $\mathrm{ms}=$ mesothorax; $\mathrm{mt}=$ metathorax; $\mathrm{pt}=$ prothorax; $\mathrm{ta}=$ tarsus; te $=$ terminal end; $\mathrm{ti}=$ tibia.

a slightly wider posterior part. A low value indicates a rounded convex anterior part and a somewhat narrower posterior part (Suppl. Fig. 1).

PC2 explains $13.11 \%$ of the total variance. It is mainly influenced by the length and shape of the posterior part of the terminal end. A high value indicates a stouter terminal end with rounder convex anterior and posterior part. A low value indicates a more drawn-out straighter anterior part and a more pointed posterior part (Suppl. Fig. 1).

PC 3 explains $6.20 \%$ of the total variance. It is mainly influenced by the width and shape of the anterior part and the length of the posterior part of the terminal end. A high value indicates a rounder anterior part of the terminal end and a longer posterior part. A low value indicates a straighter anterior part and a shorter posterior part (Suppl. Fig. 1).

PC 4 explains $2.80 \%$ of the total variance. It is mainly influenced by the shape of the anterior part of the terminal end. A high value indicates a convex anterior part of the terminal end. A low value indicates a concave anterior part (Suppl. Fig. 1).

PC 5 explains $2.02 \%$ of the total variance. It is mainly influenced by the length of the posterior 

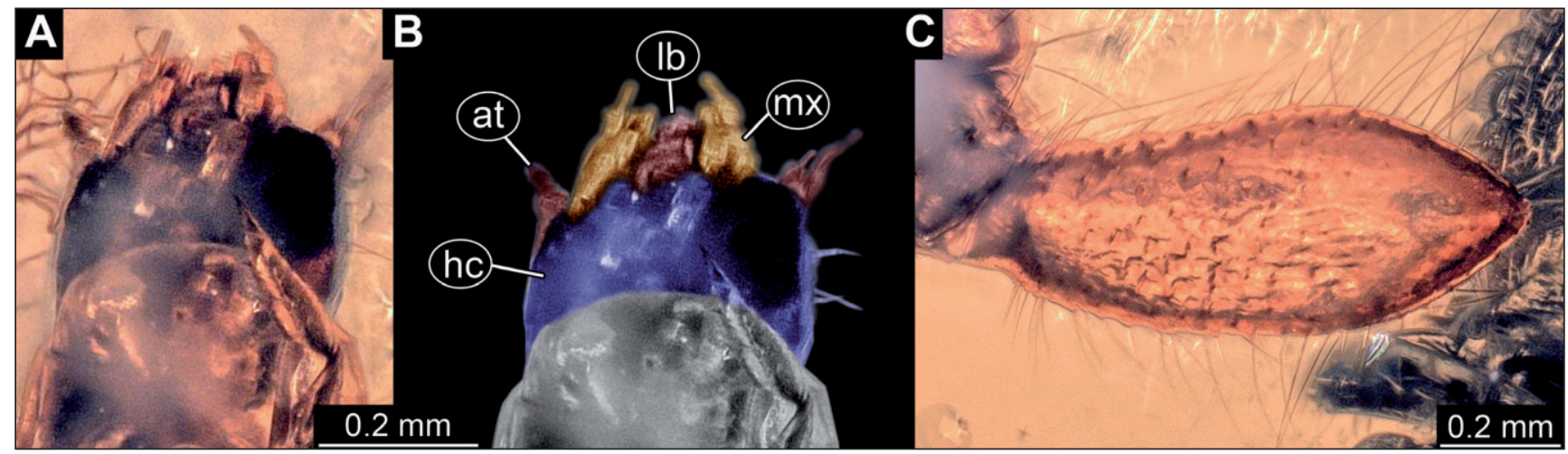

Fig. 12 - Close-up details of larva of Scraptiidae, specimen PED 0892; all composite images. A) Head in ventral view. B) Colour-marked version of (A). C) Terminal end in ventral view. Abbreviations: at $=$ antenna; $\mathrm{hc}=$ head capsule; $\mathrm{lb}=\mathrm{labium} ; \mathrm{mx}=$ maxilla.

part of the terminal end. A high value indicates a pointed posterior part of the terminal end. A low value indicates a rounder posterior part (Suppl. Fig. 1).

When plotting principal components 1 and 2, the areas occupied by extant and fossil specimens partially overlap in the morphospace (Fig. 17). Yet, there is a tendency of extant specimens plotting more or less equally around the centre of the plot, whereas the Eocene specimens plotting left of the Y-axis, with the exception of two specimens (from Gröhn 2015 and SMF-Be 10735 from this contribution). Interestingly, the two Cretaceous specimens plot far from each other: specimen PED 1108 plots in the left lower quadrant of the scatter plot, whereas PED 0483 plots in the right lower quadrant of the plot.

We further checked for possible correlations including: head width over body length (Fig. 18A), terminal end length over body length (Fig. 18B), PC1 over body length (Fig. 18C) and PC2 over body length (Fig. 18D).

Plotting head width over body length (Fig. 18A) shows that Eocene and extant specimens clearly form two groups with the exception of one specimen of the Eocene group (from Weitschat \& Wichard 2002). The Eocene group plots in the lower left part of the plot, with the single specimen plotting in the upper right part of the plot. The two Cretaceous specimens have similarly long body, but the difference in the width of head capsules positions them far apart on the Y-axis in the middle of the plot.

Plotting terminal end length over body length (Fig. 18B) shows that Eocene and extant specimens form two groups, except for one specimen of the
Eocene group (from Weitschat \& Wichard 2002) that plots in the upper right corner of the plot. Eocene specimens plot more to the left and the extant specimens plot more to the right of the plot. Cretaceous specimens plot together in the area of $4 \mathrm{~mm}$ on $\mathrm{X}$-axis and between $0.6-0.8 \mathrm{~mm}$ on Y-axis. Part of the extant and Eocene specimens overlap with the position of Cretaceous ones.

When plotting PC1 (shape and length of the anterior part of the terminal end) over the body length (Fig. 18C) extant and Eocene specimens form two more or less distinct groupings. However, two specimens (from Gröhn 2015 and Weitschat \& Wichard 2002) from the Eocene behave as outliers. Cretaceous specimens are far apart from each other, but both plot closer to Eocene than to extant specimens.

When plotting PC2 (shape and length of the posterior part of the terminal end) over body length (Fig. 18D), specimens of all three time periods aggregate on the left side of the plot, followed by an area of extant specimens in the middle, and one Eocene specimen (from Weitschat \& Wichard 2002) plotting further right, far away from the rest of the Eocene specimens.

\section{Discussion}

\section{Occurrence of the larvae of the group Scraptiidae}

Based on the numerous specimens we report in this study it seems that immatures of the group Scraptiidae with prominent terminal ends are more common than earlier anticipated. Still, it is surprising given the quite important ecosystem function 


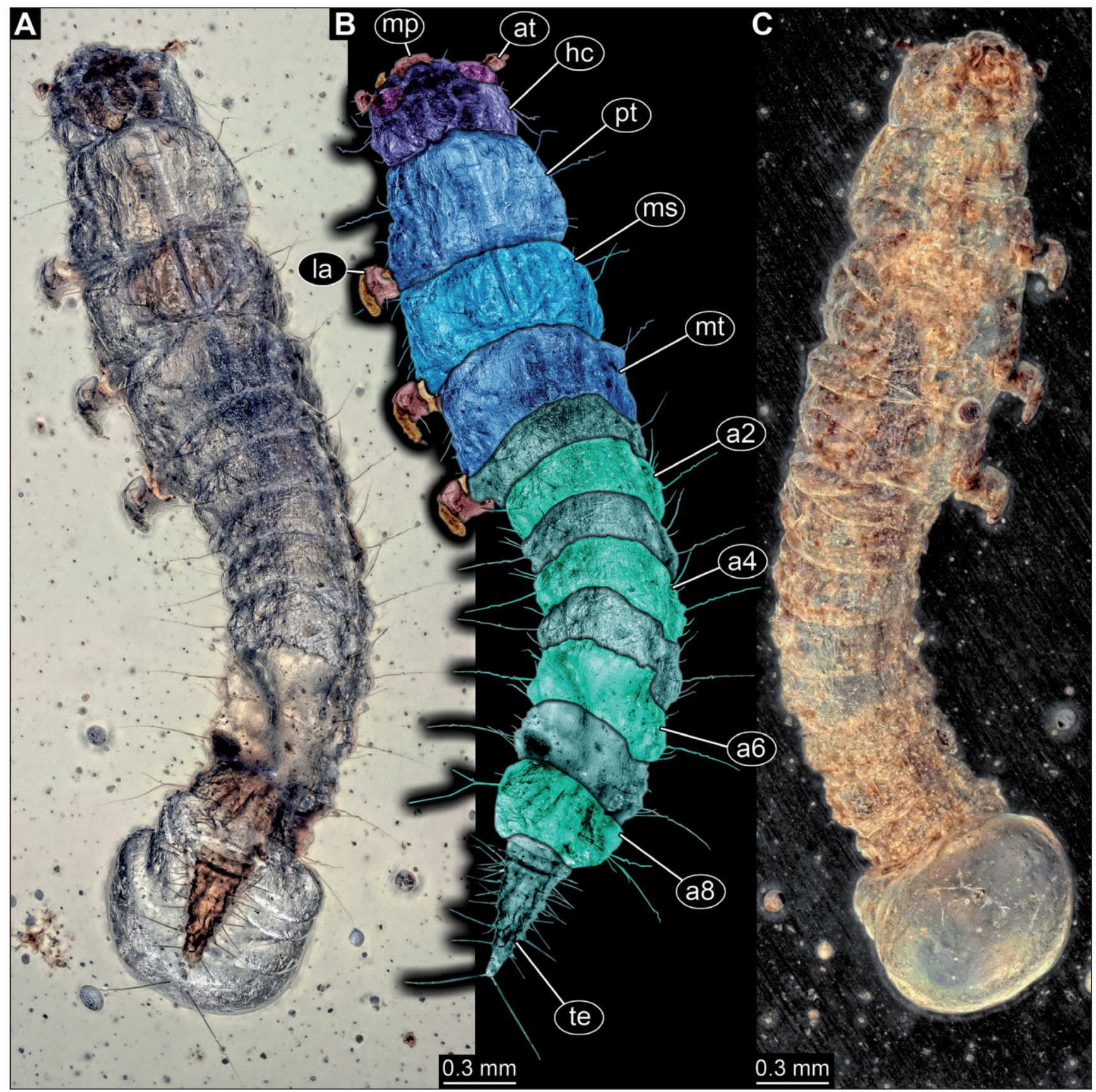

Fig. 13 - Larva of Scraptiidae preserved in Myanmar amber, specimen PED 1108; all composite images. A) Habitus in dorsal view, nonpolarised ring illumination on white background. B) Colour-marked version of (A). C) Habitus in ventral view, non-polarised ring illumination on black background. Abbreviations: a2 $-8=$ abdomen segments $2-8$; at $=$ antenna; hc $=$ head capsule; la $=$ locomotory appendage; $\mathrm{mp}=$ mouth parts; $\mathrm{ms}=$ mesothorax; $\mathrm{mt}=$ metathorax; $\mathrm{pt}=$ prothorax $;$ te $=$ terminal end .

of the larvae, which are involved in carbon cycling, that there are still so few records of these larvae.

The new finds reported expand especially the record of these larvae in Eocene amber. It seems not surprising to find tree- or wood-associated larvae such as those of Scraptiidae in amber. Their original habitat is clearly close enough to the source of tree resin to have the larvae trapped in it to become fossilised as amber inclusions. Again, it ap- pears that the so far seeming rarity of these larvae is only an effect of not reporting such larvae, despite their principal availability (see Baranov et al. 2020, 2021).

A still to be expanded part of the sample is that of the modern fauna. Although we could report here new specimens from databases, we know now almost as many fossil specimens as extant ones, and the fossil ones have been better documented 




Fig. 14 - Close-up details of the larva of Scraptiidae, specimen PED 1108; all composite images. A) Head in dorsal view. B) Terminal end in dorsal view. C) Head in ventral view. D) Locomotory appendages. E) Colour-marked version of (D). Abbreviations: at $=$ antenna; $\mathrm{cx}$ $=$ coxa $; \mathrm{fe}=$ femur; $\mathrm{mp}=$ mouth parts; $\mathrm{ta}=$ tarsus; $\mathrm{ti}=$ tibia; $\mathrm{tr}=$ trochanter.

than some of the extant ones. Though searching for them, we have so far failed in identifying additional extant specimens in museum collections. Field collecting will be necessary to further improve this situation.

\section{The group Scraptiidae in the Cretaceous}

It has been known from the literature that representatives of the group Scraptiidae should be present already in the Cretaceous (Peris et al. 2016a, b; Peris \& Rust 2020). Willemstein (1987) presumed their existence in the Cretaceous as the presumed closely related group Mordellidae was dated back to the Jurassic (Ščegoleva-Barovskaya 1929). Rasnitsyn (1988) mentioned that the group Scraptiidae should be known also from the Late Jurassic, but newer studies did not further support this idea. In more recent literature, specimens of this group have been listed for Siberian, Iberian, French and Myanmar amber, but have not yet been studied in detail (Zherikhin \& Sukacheva 1973; Rasnitsyn \& Ross 2000; Peris et al. 2016a, b). The only depiction of false flower beetles in Cretaceous ambers we came across is that of two adult specimens (Peris et al. 2016b, their fig. 6c). Yet, this was a preliminary report in the form of a congress contribution.

Here we report two larvae of Scraptiidae from the Cretaceous period. It appears that these are the oldest larvae of false flower beetles so far. This does not only further demonstrate the presence of this group, but also of this special type of larva. As not all species of Scraptiidae have larval stages with enlarged terminal ends, the presence of the group is not equivalent to the presence of a specific larval morphology (see discussion in Haug \& Haug 2017; Baranov et al. 2020). 


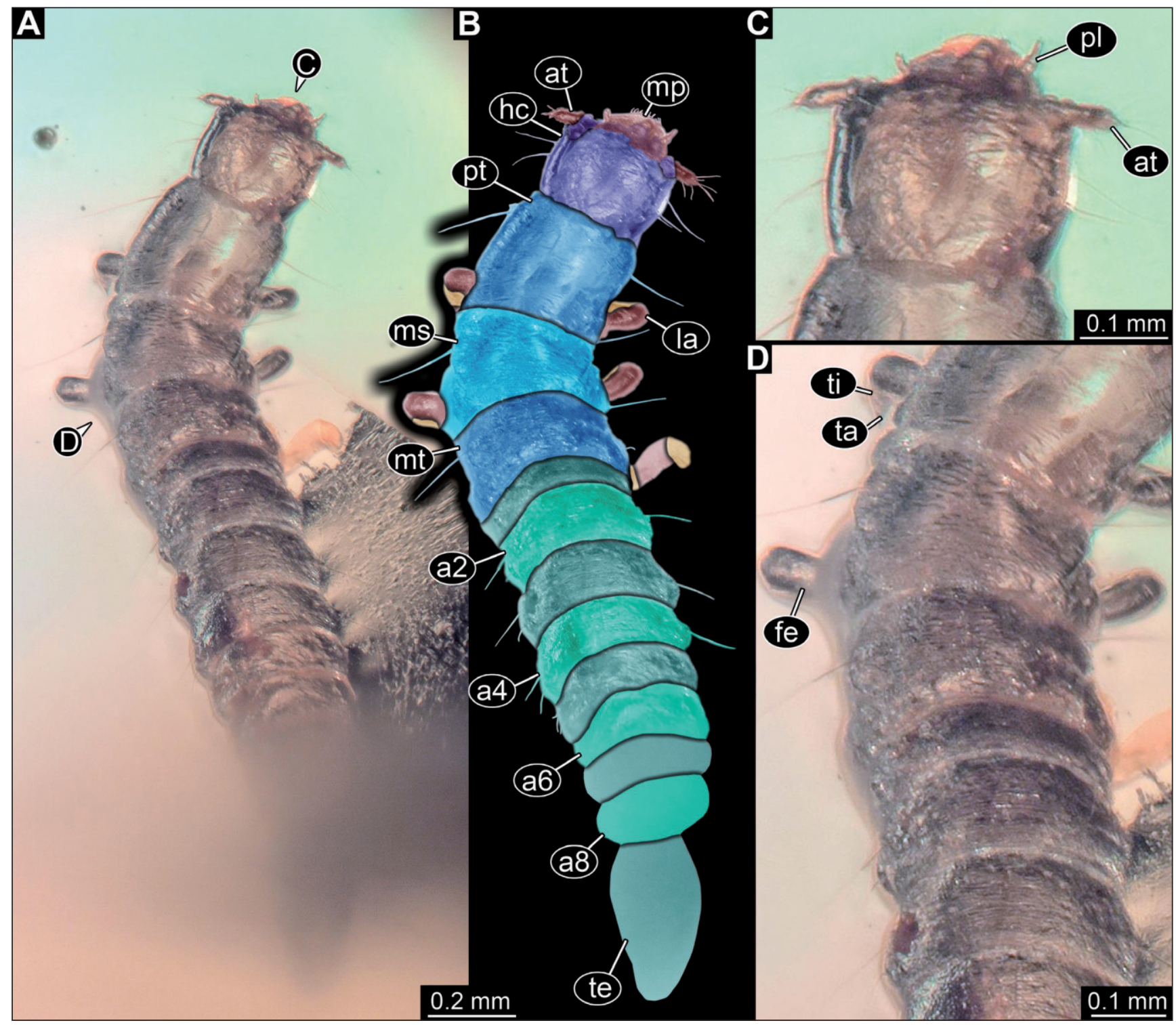

Fig. 15 - Larva of Scraptiidae preserved in Baltic amber, specimen SMF_Be 10659; all composite images. A) Habitus in dorsal view, crosspolarised co-axial light on white background. B) Colour-marked version of (A). C-D) Close-ups. C - Head in dorsal view. D - Part of trunk with locomotory appendages. Abbreviations: a2 $-8=$ abdomen segments $2-8$; at $=$ antenna; fe $=$ femur; hc $=$ head capsule; $\mathrm{la}=$ locomotory appendage; $\mathrm{mp}=$ mouth parts; $\mathrm{ms}=$ mesothorax; $\mathrm{mt}=$ metathorax; $\mathrm{pl}=\mathrm{palp} ; \mathrm{pt}=$ prothorax; $\mathrm{ta}=$ tarsus; te $=$ terminal end; ti $=$ tibia.

The Cretaceous larvae resemble modern and Eocene larvae in possessing elongated terminal ends. We therefore assume that these larvae are also involved in carbon cycling. Many organisms in Cretaceous ambers are completely or partially saproxylic organisms (Peris et al. 2016a) with an important role in wood decomposition (Tate et al. 1993; Grove 2002). Also, saproxylicity seems to be the most common mode of life in extant beetles (Gimmel \& Ferro 2018). It should therefore be indeed quite likely that the fossil larvae with enlarged terminal ends had such a life style.
Whether the rarity of representatives from Cretaceous is due to lack of reporting or due to lack of preserved specimens in Cretaceous amber (possibly due to a true rarity in the fauna) remains unknown. Often a first report of a specific type of fossil from amber triggers the report of further ones.

Variation in terminal end morphology within fossil and extant representatives

The specimens studied in this paper show diversity of exact morphology of terminal ends. In 


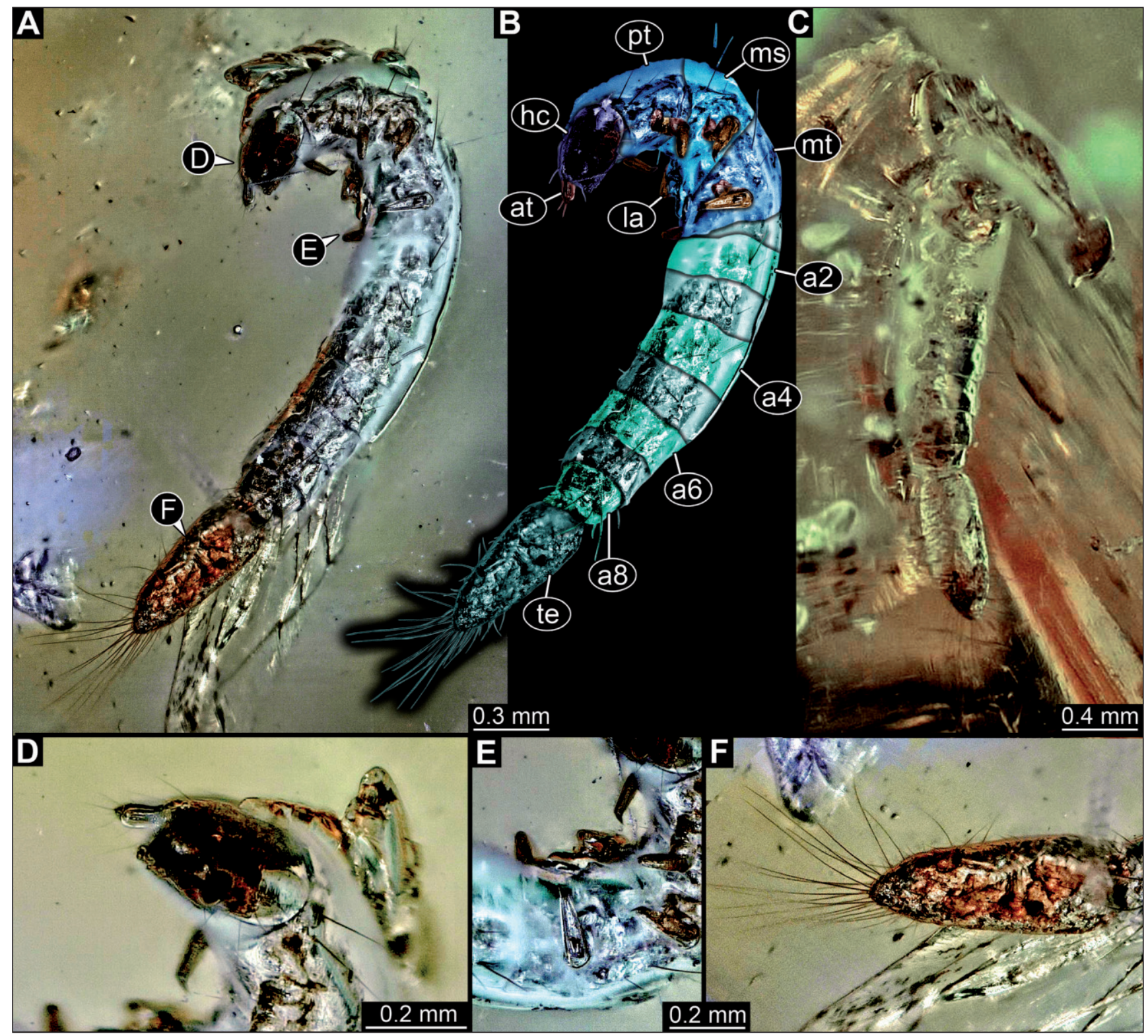

Fig. 16 - Larva of Scraptiidae preserved in Baltic amber, specimen SMF_Be 10735; all composite images. A) Habitus in lateral view, nonpolarised ring illumination on white background. B) Colour-marked version of (A). C) Dorsolateral view of the head and thorax and ventral view of the abdomen, non-polarised ring illumination on white background. D-F) Close-ups. D - Head in lateral view. E - Locomotory appendages. F - Terminal end in lateral view. Abbreviations: $\mathrm{a} 2-8=$ abdomen segments 2-8; at $=$ antenna; hc $=$ head capsule; $\mathrm{la}=$ locomotory appendage; $\mathrm{ms}=$ mesothorax; $\mathrm{mt}=$ metathorax; $\mathrm{pt}=$ prothorax; $\mathrm{te}=$ terminal end .

the scatter plot PC2 over PC1 (Fig. 17) several more or less distinct groups can be recognised. The larvae from the Eocene plot mostly on the left side of the Y-axis, as they have more rounded anterior and narrower posterior part of the terminal end than the extant larvae. The larvae that plot under the X-axis have more drawn-out anterior part and pointier posterior part.

Among the larvae from Eocene amber, there are two that do not group with the others (specimen from Gröhn 2015 and SNSB-BSPG 2018 III 336). However, the larva from Gröhn (2015) might plot this way due to a very different left and right side of the terminal end and the mirroring of one part of the terminal end for the shape analysis. Therefore, the morphology of the terminal end of this larva might be artificial, i.e. an effect of embedding and preservation.

The second larva (SNSB-BSPG 2018 III 336) has indeed a very stout terminal end with rounded anterior and posterior parts (Fig. 5). This appears to be original morphology and not caused by deformation during embedding. The difference in morphology might reflect differences in species identity 
Fig. 17 - Scatterplot of PC2 over PC1. Extant specimens are presented in grey, Eocene specimens in black, and Cretaceous ones in white. All terminal ends used in this study are presented around the plot.

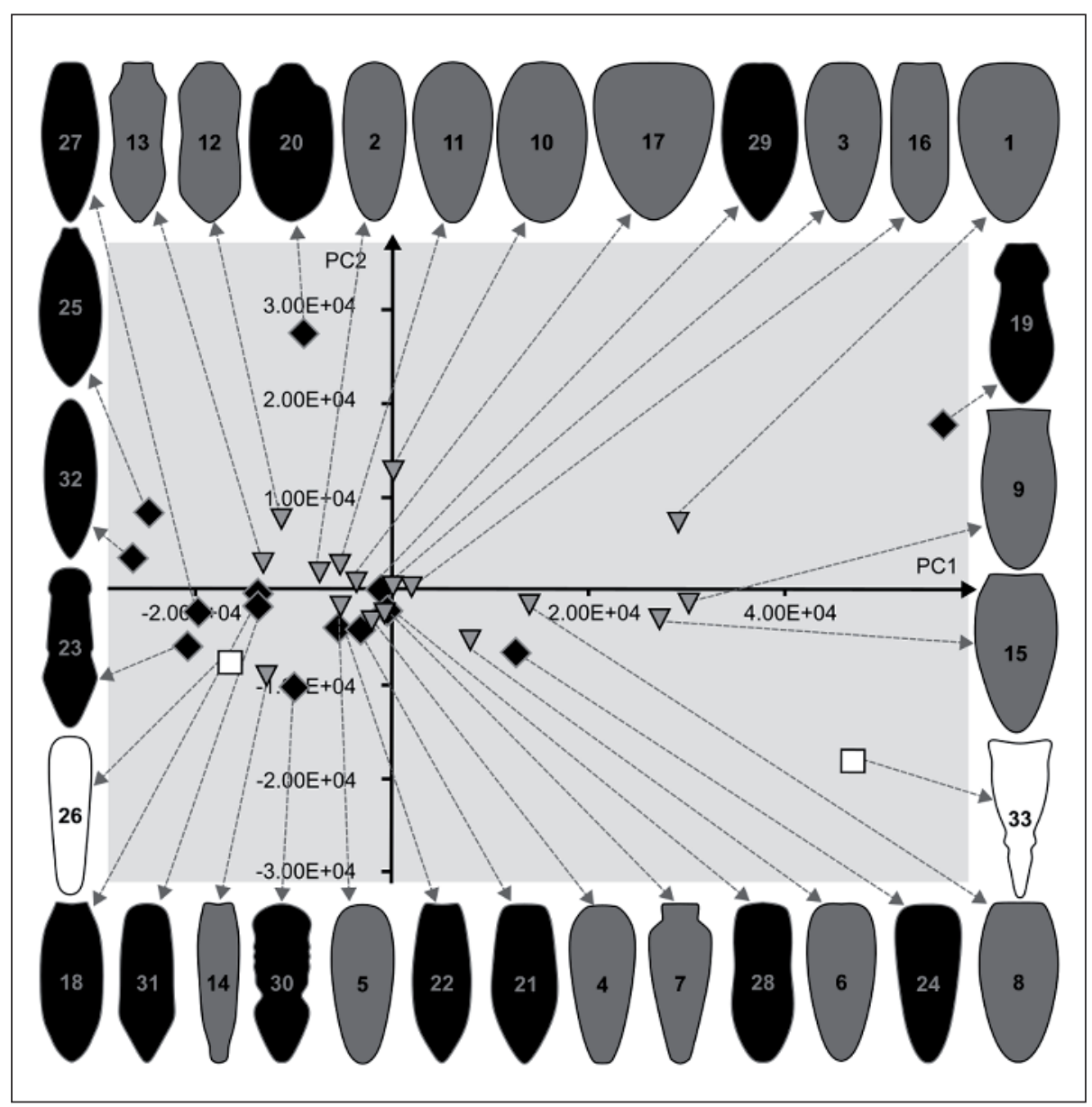

or the developmental stage (see also further below). Yet, there may be also other biological causes for differences. In the very large last larval stage, the formation of the pre-pupa may deform the shape of a larva, as it seems common in holometabolans (e.g. Haug et al. 2020c, their fig. 3d). Yet the larva appears not to be very large and is unlikely to represent such a late stage. In larvae with enlarged terminal ends there is another possible cause, related to the autotomy. If the autotomy happened in an early larval stage, we can expect regeneration of the terminal end. We so far found no example how such a regenerating terminal end will look like.

The terminal end of the larva SNSB-BSPG 2018 III 232 shows great similarity with specimen PED 0006 from Haug \& Haug (2019, their fig. 2) in having an elongated and a heart-shaped posterior part of the terminal end. This supports the idea that this shape of the terminal end is not an artefact caused by preservation but a true original morphology. Such a shape has not been recorded in the modern fauna and might represent a now-extinct type of morphology.

\section{Differences between Eocene and extant} larvae

The extant larvae plot closer together in the PC2 versus PC1 scatter plot than the Eocene larvae (Fig. 17). Concerning the general position of the groups, the extant larvae plot more to the right than the larvae from the Eocene.

On the scatter plot of head width versus body length (Fig. 18A) the specimens from the three time periods show clear differences. The specimens from the Eocene seem to be generally smaller than the extant specimens, with a single exception (the specimen from Weitschat \& Wichard 2002). Interestingly, the Cretaceous specimens plot in the middle region and fall in body length between extant and Eocene groups.

Plotting length of the terminal end and body length (Fig. 18B) yielded similar results as the plot of head width over body length. The specimens from the Eocene are generally smaller than the extant specimens and Cretaceous specimens plot in between the other two groups.

If we would assume that these larvae all be- 


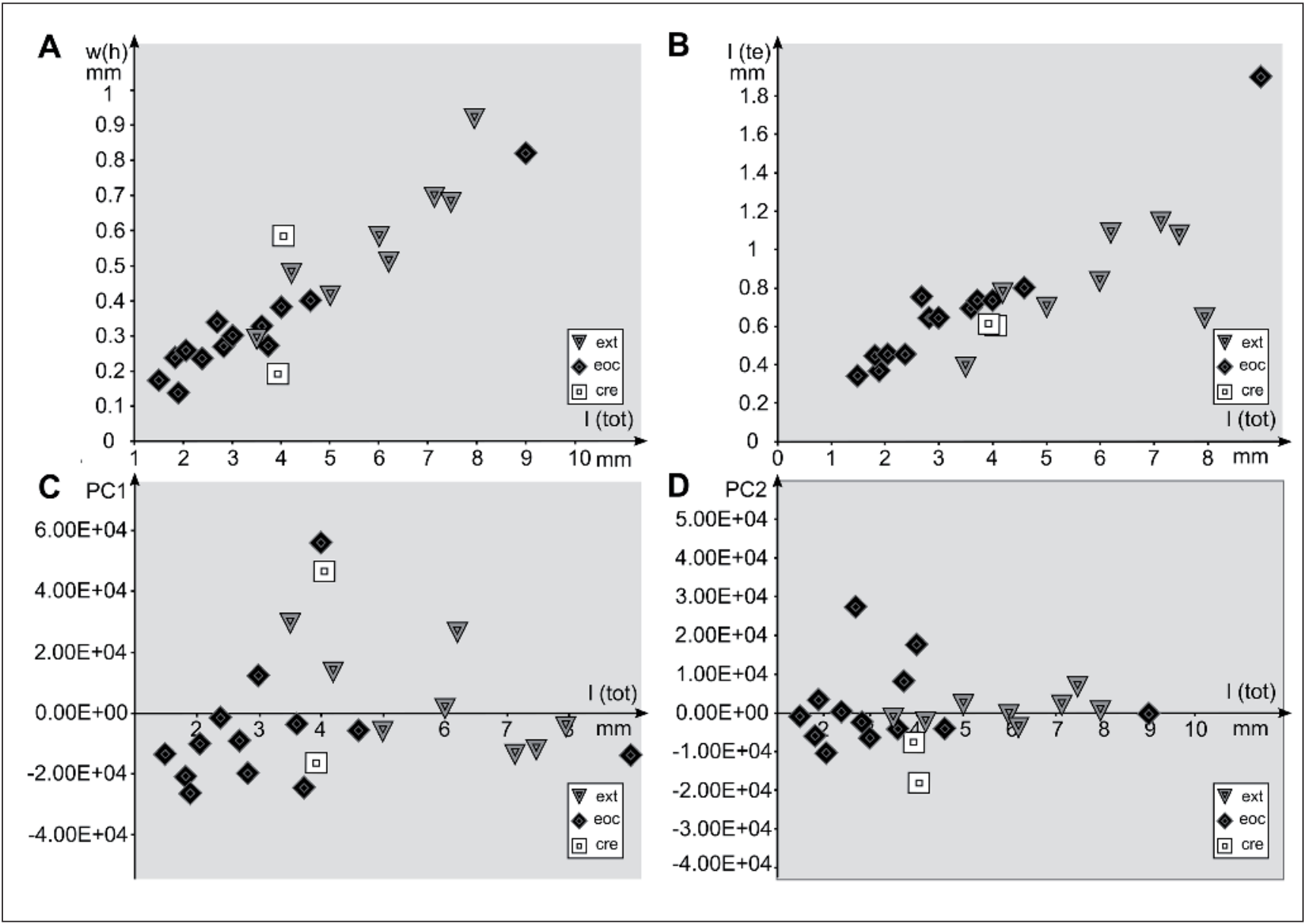

Fig. 18 - Additional quantitative aspects of Scraptiidae with large terminal ends. A) Scatterplot of head capsule width over total body length (six extant specimens from Bonn were left out since the scale was unreadable). B) Scatterplot of terminal end length over total body length. C) Scatterplot of PC1 over total body length. D) Scatterplot of PC2 over total body length.

long to the same larval stage it would mean that the Cretaceous specimens were, in general, smaller than the extant ones and bigger than Eocene ones. In reality, it is possible that what we see in the Eocene are just earlier developmental stages of larvae, while we know only later extant larval stages (see also Haug \& Haug 2019). Hence, although we have increased the sample size, we are left with a similar uncertainty as already discussed in Haug \& Haug (2019).

Another recognisable difference is the relative length of the terminal end. It appears that the terminal end of extant specimens takes a smaller percentage of the body length than the terminal ends of the fossil larvae. As already discussed in Haug \& Haug (2019) this might indicate either a specific morphology not known in the modern fauna, and therefore may represent a now-extinct larval morphology or represent a part of the larval phase not known from extant species because it has not been recorded yet.

\section{Differences of the Cretaceous specimens}

The two larvae from the Cretaceous (PED 0483 and PED 1108) plot quite far apart from each other, both plotting in low values of the PC2 axis (Fig. 17), which indicates more drawn-out anterior part and more pointed posterior part of the terminal end. However, PED 1108 has a much lower value than PED 0483. We can recognise a certain degree of qualitative similarity of the terminal ends (Figs. 9C, 14B), where they both have a more triangular shape from a dorsal view than any specimen from a younger geological age.

The posterior end of specimen PED 1108 is partially concealed by a whitish film. It is possible that this is a liquid expelled from the terminal end as a defensive act. More precisely the larva might have tried to autotomize the terminal end to escape from the still liquid resin; yet if this was indeed the case then apparently without much success. 


\section{Conclusions}

The new specimens reported here demonstrate some additional aspects of larvae of the group Scraptiidae with enlarged terminal ends. These include:

- The larvae are more common than so far anticipated, especially in Eocene Baltic amber.

- This special larval type was already present in the Cretaceous, although there are some slight differences in the shape of the terminal end (being more triangular).

- The diversity of the terminal ends might have been larger in the Eocene, yet it remains unclear whether this is coupled to the fact that we have so far not seen earlier larval stages in the modern fauna (as already discussed in Haug \& Haug 2019).

Acknowledgements: This study heavily benefited from the help of various people and institutions; we thank them for their support. Our thanks go to Artur Michalski, Wroclaw, Andrey Krylov, Kaliningrad, and Peter Laging, Scharnebeck for providing specimens. Mónica M. Solórzano-Kraemer, Frankfurt, and Mike Reich, Munich, are thanked for providing access to specimens. J. Matthias Starck, Munich, is thanked for long time support. JTH is kindly supported by the Volkswagen Foundation with a Lichtenberg Professorship and by the German Research Foundation (DFG Ha-6300/6-1). CH was funded via the LMU excellent Junior Researcher Fund and an award for equal opportunities for women in research of the LMU Munich. We are grateful to all people providing free software used in this project. This is LEON publication \#23.

\section{REFERENCES}

Badano D., Engel M.S., Basso A., Wang B. \& Cerretti P. (2018) - Diverse Cretaceous larvae reveal the evolutionary and behavioural history of antlions and lacewings. Nature Communications, 9: 1-14.

Baranov V.A., Wang Y., Wedmann S. \& Haug J.T. (2020) - Ecomorphological diversity of larvae of soldier flies and their closest relatives in deep time. PeerJ, 8: e10356.

Baranov V.A., Engel M.S., Hammel J., Hörnig M.K., van de Kamp T., Zuber M. \& Haug J.T. (2021) - Synchrotronradiation computed tomography uncovers ecosystem functions of fly larvae in an Eocene forest. Palaeontologia Electronica, 24: a07.

Böving A.G. \& Craighead F.C. (1931) - An illustrated synopsis of the principal larval forms of the order Coleoptera. Entomologica Americana (NS), 11:1-351.

Braig F., Haug J.T., Schädel M. \& Haug C. (2019) - A new thylacocephalan crustacean from the Upper Jurassic lithographic limestones of southern Germany and the diversity of Thylacocephala. Palaeodiversity, 12: 69-87.

Buck F.D. (1954) - Coleoptera: Lagriidae, Alleculidae, Melandryidae, Salpingidae, Pythidae, Mycteridae, Oede- meridae, Mordellidae, Scraptiidae, Pyrochroidae, Rhipiphoridae, Anthicidae, Aderidae and Meloidae. Handbk. Ident. Br. Insects, 5(9). Royal Entomological Society of London, $30 \mathrm{pp}$.

Crowson R.A. (1955) - The classification of the families of British Coleoptera (part). Entomologist's Monthly Magazine, 86: 56-57.

Gimmel M.L. \& Ferro M.L. (2018) - General overview of saproxylic Coleoptera. In: Ulyshen M.D. (Ed.) - Saproxylic insects: diversity, ecology and conservation: 51-128. Springer, Heidelberg.

Gröhn C. (2015) - Einschlüsse im baltischen Bernstein. Wachholtz Verlag -Murmann Publishers, Kiel, 424 pp.

Grove S.J. (2002) - Saproxylic insect ecology and the sustainable management of forests. Annual Review of Ecology, Evolution, and Systematics, 33: 1-23.

Harrington B. et al. (2004-2005) Inkscape http://www.inkscape.org

Haug G.T., Haug C., Pazinato P., Braig F., Perrichot V., Gröhn C., Müller P. \& Haug J.T. (2020b) - The decline of silky lacewings and morphological diversity of long-nosed antlion larvae through time. Palaeontologia Electronica, 23: a39.

Haug J.T., Müller C.H.G. \& Sombke A. (2013) - A centipede nymph in Baltic amber and a new approach to document amber fossils. Organisms Diversity \& Evolution, 13: 425-432.

Haug J.T. \& Haug C. (2017) - Species, populations and morphotypes through time- challenges and possible concepts. Bulletin de la Societe Géologique de France, 188: 20.

Haug J.T., Haug C., Neumann C., Sombke A. \& Hörnig M.K. (2018) - Early post-embryonic polyxenidan millipedes from Saxonian amber (Eocene). Bulletin of Geosciences, 93: $1-11$

Haug J.T. \& Haug C. (2019) - Beetle larvae with unusually large terminal ends and a fossil that beats them all (Scraptiidae, Coleoptera). PeerJ, 7: e7871.

Haug J.T., Azar D., Ross A., Szwedo J., Wang Bo, Arillo A., Baranov V., Bechteler J., Beutel R., Blagoderov V., Delclòs X., Dunlop J., Feldberg K., Feldmann R., Foth C., Fraaije R.H.B., Gehler A., Harms,D., Hedenäs L., Hyžny M., Jagt J.W.M., Jagt-Yazykova E.A., Jarzembowski E., Kerp H., Khine P.K., Kirejtshuk A.G., Klug C., Kopylov D.S., Kotthoff U., Kriwet J., McKellar R.C., Nel A., Neumann C., Nützel A., Peñalver E., Perrichot V., Pint A., Ragazzi E., Regalado L., Reich M., Rikkinen J., Sadowski E.-M., Schmidt A.R., Schneider H., Schram F.R., Schweigert G., Selden,P., Seyfullah L.J., Solórzano-Kraemer M M., Stilwell J.D., van Bakel B.W.M., Vega F.J., Wang Yongdong, Xing Lida \& Haug C. (2020a) - Comment on the letter of the Society of Vertebrate Paleontology (SVP) dated April 21, 2020 regarding "Fossils from conflict zones and reproducibility of fossil-based scientific data": Myanmar amber. PalZ, 94: 431-437.

Haug J.T., Baranov V.A., Schädel M., Müller P., Gröhn P. \& Haug C. (2020c) - Challenges for understanding lacewings: how to deal with the incomplete data from extant and fossil larvae of Nevrorthidae? (Neuroptera). Frag- 
menta entomologica, 52: 137-167.

Hayashi N. (1962) - The larval form of Anaspis (Anaspis) funagata Kono (Scraptiidae). (Studies on coleopterous larvae XIV). Entomological Review of Japan, 15: 19-21.

Hayashi N. (1980) - Illustrations for identification of larvae of the Cucujoidea (Coleoptera) found living in dead trees in Japan. Memoirs of the Education Institute for Private Schools in Japan, 72: 95-147.

Hoffeins H.W. (2001) - On the preparation and conservation of amber inclusions in artificial resin. Polskie Pismo Entomologiczne, 70: 215-219.

Iwata H. \& Ukai Y. (2002) - SHAPE: A computer program package for quantitative evaluation of biological shapes based on elliptic Fourier descriptors. Journal of Heredity, 93: 384-385.

Larsson S.G. (1978) - Baltic Amber: A Palaeobiological Study. Entomonograph I. Scandinavian Scientific Press, Klampenborg, 192 pp.

Lawrence J.F., Ślipinski A., Seago A.E., Thayer M.K., Newton A.F. \& Marvaldi A.E. (2011) - Phylogeny of the Coleoptera based on morphological characters of adults and larvae. Annals of Zoology, 61: 1-217.

Minelli A., Brena C., Deflorian G., Maruzzo D. \& Fusco G. (2006) - From embryo to adult - beyond the conventional periodization of arthropod development. Development Genes and Evolution, 216: 373-383.

Mulsant M.E. (1856) - Histoire naturèlle des Coléoptères de France. Pectinipèdes. L. Mason, Paris, 96 pp.

Peretti A. (2021) - An alternative perspective for acquisitions of amber from Myanmar including recommendations of the United Nations Human Rights Council. Journal of International Humanitarian Action, 6: 12.

Peris D. \& Rust J. (2020) - Cretaceous beetles (Insecta: Coleoptera) in amber: the palaeoecology of this most diverse group of insects. Zoological Journal of the Linnean Society, 189: 1085-1104.

Peris D., Ruzzier E., Perrichot V. \& Delclòs X. (2016a) - Evolutionary and palaeobiological implications of Coleoptera (Insecta) from Tethyan-influenced Cretaceous ambers. Geoscience Frontiers, 7: 695-706.

Peris D., Ruzzier E., Perrichot V., Penalver E. \& Delclòs X. (2016b) - Paleobiology of beetles (Insecta: Coleoptera) from Western European Cretaceous ambers. 7th International Conference on fossil Insects, Arthropods And Amber, Apr 2016, Edinburgh.

Peterson A. (1951) - Larvae of Insects. An Introduction to Nearctic Species. Part II. Coleoptera, Diptera, Neuroptera, Siphonaptera, Mecoptera, Trichoptera. Larvae of Insects. An Introduction to Nearctic Species. Edward Brothers, Columbus, 416 pp.

Poinar G. \& Ellenberger S. (2020) - Burmese amber fossils, mining, sales and profits. Geoconservation Research, 3: $12-16$.

Rasnitsyn A.P. (1988) - Problem of global crisis of land biocoenoses during the mid-Cretaceous period. In: Pono- marenko A.G. (Ed.) - Cretaceous Biocoenotic Crisis and Insect Evolution [Melovoi biotsenoticheskii krizis i evolutsiya nasekomykh]: 191-207. Nauka, Moscow.

Rasnitsyn A.P. \& Ross A.J. (2000) - A preliminary list of arthropod families present in the Burmese amber collection at The Natural History Museum, London. BulletinNatural History Museum Geology Series, 56: 21-24.

Rayfield E.J., Theodor J.M. \& Polly P.D. (2020) - Fossils from conflict zones and reproducibility of fossil-based scientific data. Society of Vertebrate Paleontology, letter, 21/04/2020. https://vertpaleo.org/wp-content/uploads/2021/01/SVP-Letter-to-Editors-FINAL.pdf, retrieved on 04 September 2021

Society of Vertebrate Paleontology's Myanmar Working Group 2021. Recommendations for Researchers, Research Institutions, and Publishers for Myanmar Amber. Updated 08/06/2021. https://vertpaleo.org/wp-content/uploads/2021/06/SVP-Recommendations-forResearchers-Research-Institutions-and-Publishers-forMyanmar-Amber.pdf, retrieved on 04 September 2021.

Ščegoleva-Barovskaya T. (1929) - Der erste Vertreter der Familie Mordellidae (Coleoptera) aus der Juraformation Turkestans. Comptes Rendus de l'Academie des Sciences de l'URSS, 8: 27-29.

Švácha P. (1995) - The larva of Scraptia fuscula (P.W.J. Müller) (Coleoptera: Scraptiidae): autotomy and regeneration of the caudal appendage. In: Pkaluk J. \& Ślipiński S.A. (Eds.) -Biology, Phylogeny, and Classification of Coleoptera: Papers Celebrating the 80th Birthday of Roy A. Crowson: 473-489. Muzeum i Instytut Zoologii PAN, Warszawa.

Tate K.R., Ross D.J., O’Brien B.J. \& Kelliher F.M. (1993) - Carbon storage and turnover, and respiratory activity, in the litter and soil of an old-growth southern beech (Nothofagus) forest. Soil Biology \& Biochemistry, 25: 1601-1612.

Van Emden F.I. (1942) - Larvae of British beetles. III. Keys to the families. Entomologist's Monthly Magazine, 78: 206-272.

Vanin S.A., Ide S., Casari S.A. \& Costa C. (1996) - Larvae of Neotropical Coleoptera, XXIV: Scraptia triangularis Champion, description of immatures and redescription of adult (Tenebrionoidea, Scraptiidae). Revista Brasileira de Entomologia, 40: 89-96.

Weitschat W., \& Wichard W. (2002) - Atlas of Plants and Animals in Baltic Amber. Verlag Dr. Friedrich Pfeil, München, 1-256 pp.

Willemstein S.C. (1987) - An evolutionary basis for pollination ecology (Vol. 10). J. Brill Archive/Leiden University Press, Leiden, 1-425 pp.

Young D.K. (1987) - Scraptiidae (Tenebrionoidea) In: Stehr F.W. (Ed.) - Immature Insects 2: 555-556. Kendall/ Hunt Publishing Company, Dubuque.

Zherikhin V.V. \& Sukacheva I.D. (1973) - O melovykh nasekomonosnykh yantaryakh (retinitakh) severa Sibiri. In: Nartchuk E.P. (Ed.) - Voprosy Paleontologii Nasekomykh: 3-48. Nauka, Leningrad. 